\title{
A Diagnosis of the Explosive Development of Two Extratropical Cyclones
}

\author{
ANTHONY R. LUPO AND PHILLIP J. SMITH \\ Department of Earth and Atmospheric Sciences, Purdue University, West Lafayette, Indiana \\ PETER ZWACK \\ Department of Physics, University of Quebec at Montreal, Montreal, Quebec, Canada
}

(Manuscript received 10 July 1991, in final form 18 November 1991)

\begin{abstract}
This paper examines the 24-h explosive development periods of two extratropical cyclones, the first occurring over the Gulf Stream off the coast of New England from 18 to 19 January 1979 and the second occurring over the southeastern United States from 20 to 21 January 1979. The data used in this study are the First GARP (Global Atmospheric Research Program) Global Experiment (FGGE) level IIIb (SOP I) global analyses on a $4^{\circ}$ latitude $\times 5^{\circ}$ longitude grid. The parameter used to diagnose development is the geostrophic relative vorticity tendency calculated using an extended form of the Zwack-Okossi development equation. This development equation is similar to the Petterssen-Sutcliffe development equation, but is shown to be more complete by explicitly coupling surface development with forcing at all levels above the surface. Cyclonic-vorticity advection, warm-air advection, and latent heat release act to develop the two cyclones, while adiabatic cooling in the ascending air opposes development. Further, vertical profiles of the development quantities for these two cases reveal that vorticity and temperature advection maximize in the $200-300-\mathrm{mb}$ layer, while the latent heat release maximum is typically below $500 \mathrm{mb}$.
\end{abstract}

\section{Introduction}

In recent years, interest in extratropical cyclone development has focused on cyclone events that develop explosively. Referring to these cyclones as "bombs," Sanders and Gyakum (1980) define explosive cyclogenesis as a reduction of the cyclone's central sea level pressure at a rate of 1 bergeron or greater, defined as $24 \mathrm{mb}(24 \mathrm{~h})^{-1}$ multiplied by the factor $(\sin \phi / \sin 60)$, where $\phi$ is the latitude of the cyclone center at the midpoint of the 24-h period. In their construction of a 3-yr climatology, Sanders and Gyakum noted that explosive cyclogenesis is primarily a cold-season event with maximum occurrences in the month of January. They also noted that most explosive cyclogenesis occurs over the oceans just to the east of the major continental landmasses in the Northern Hemisphere. However, an appreciable number of cases also occur over land in the southeastern United States. Sanders and Gyakum also found that explosive cyclogenesis typically occurs about $500 \mathrm{~km}$ ahead of a moving 500 -mb trough within or poleward of the jet stream and underneath upperlevel diffluence, and noted the importance of low-level baroclinicity and diabatic heating processes. Roebber (1984) updated the climatology of Sanders and

Corresponding author address: Dr. Phillip J. Smith, Department of Earth and Atmospheric Sciences, Purdue University, 1397 Civil Engineering Bldg., West Lafayette, IN 47907-1397.
Gyakum for an additional three years, through 1982, and confirmed the importance of these mechanisms.

In addition, research during the decade of the $1980 \mathrm{~s}$ has revealed the importance of other mechanisms in explosive cyclone development. Uccellini et al. (1985) and Elsberry and Kirchoffer (1988) demonstrated the importance of tropopause folding and the extrusion of high potential vorticity stratospheric air into the troposphere. These and other authors (e.g., Uccellini et al. 1984; Reed and Albright 1986; and Uccellini and Kocin 1987) noted the importance of the superposition of favorable jet-maxima quadrants over surface cyclones. Sanders (1986) and MacDonald and Reiter (1988) expressed the importance of upper-tropospheric vorticity maxima and advections, while other authors have noted the importance of diabatic heating processes (e.g., Gyakum 1983a,b; Kuo and Reed 1988; Reed et al. 1988), lowered static stability (e.g., Nuss and Anthes 1987; Sanders 1986), and high sea surface temperature gradients (Sanders 1986; Davis and Emanuel 1988; MacDonald and Reiter 1988). Clearly, all of these processes can contribute to the growth and development of any cyclone. However, Uccellini et al. (1987) suggest that no one process is by itself responsible or sufficient for explosive development, but rather a combination of these processes is most likely required.

This study examines the synoptic-scale forcing mechanisms present during the explosive development period of two cyclone cases. The explosive development period of the first case (referred to as the marine case) 


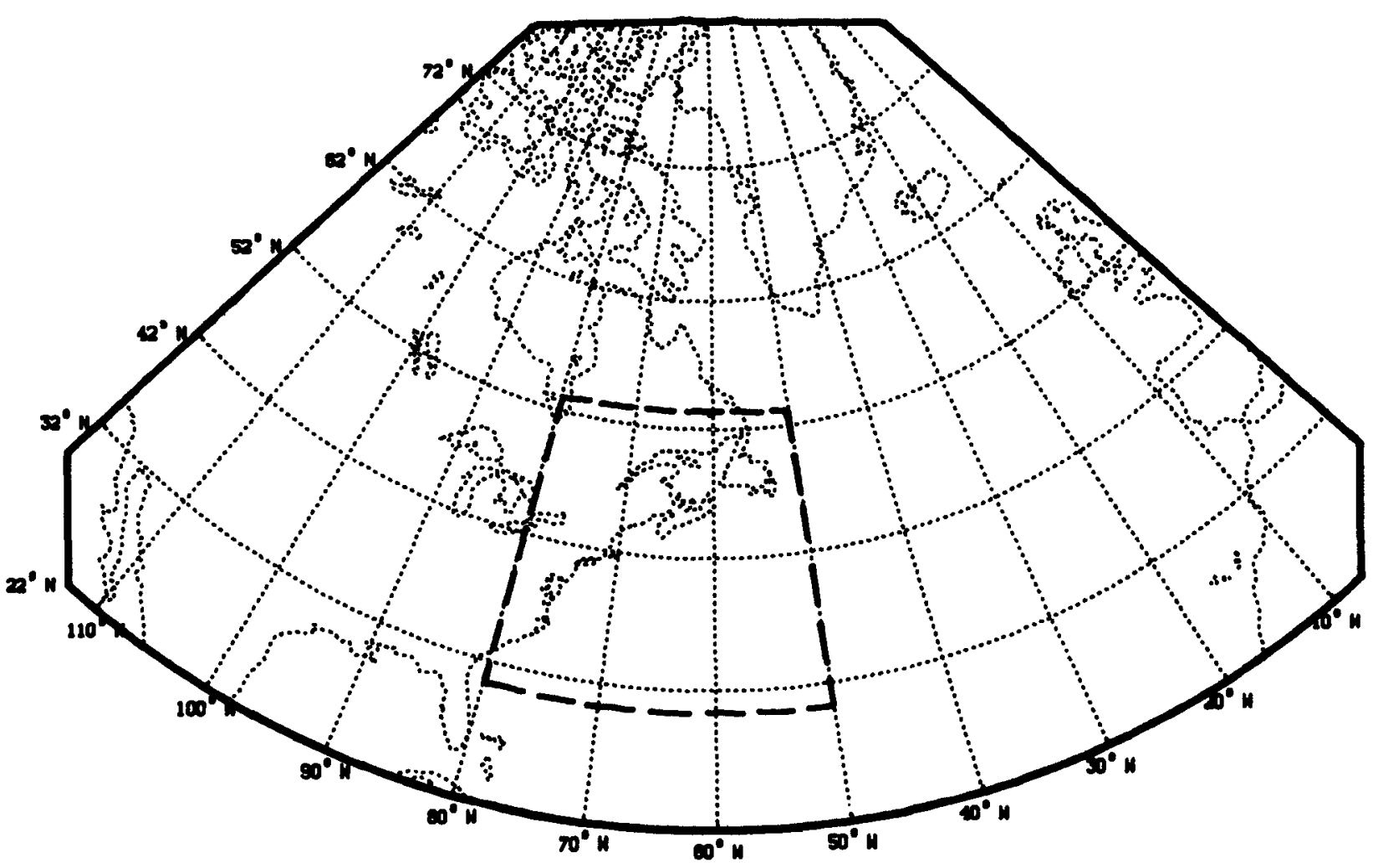

Fig. 1. Large area corresponds to the total data domain. Dashed area is an example of the cyclone area domain.

occurred in the 24-h period from 1200 UTC 18 January to 1200 UTC 19 January 1979 over the Atlantic Ocean off the New England coast and south of Nova Scotia. During that time, the cyclone's central pressure fell 31 $\mathrm{mb}$, a development rate of 1.67 bergerons at the cyclone's mean latitude of $42^{\circ} \mathrm{N}$. The second case (referred to as the land case) followed and occurred southwest of the marine case. The explosive phase of this cyclone extended through the 24-h period from 1200 UTC 20 January to 1200 UTC 21 January 1979 over the southeastern United States. During this period the central pressure fell $20 \mathrm{mb}$, a rate of 1.29 bergerons at the cyclone's mean latitude of $36^{\circ} \mathrm{N}$.

The principal objective of this research is to establish and compare the mechanisms responsible for the explosive development of two cyclone cases, each over very different geographical domains. In addition, the study provides an opportunity to test the utility of a diagnostic relationship that is quite different from those applied in previous papers. This relationship, known as the Zwack-Okossi (Z-O) development equation (Zwack and Okossi 1986), explicitly couples surface development (expressed in terms of geostrophic vorticity tendency) with forcing processes at all levels of the atmosphere. It should also be noted at the outset that the spatial $\left(4^{\circ}\right.$ latitude $\times 5^{\circ}$ longitude $)$ and temporal $(12-\mathrm{h})$ resolution of the analysis fields used in this study precludes the diagnosis of any subsynoptic- scale features that may be present during the evolution of the two cyclone cases. However, the results will show that when an appropriate form of the $\mathrm{Z}-\mathrm{O}$ equation is applied the analysis resolution is sufficient to capture synoptic-scale development features of the two cyclones.

\section{Diagnostic equations}

\section{a. The Zwack-Okossi development equation}

The parameter used to diagnose development in this study is the geostrophic relative vorticity tendency at

TABLE 1. Boundaries for cyclone calculations.

\begin{tabular}{ccc}
\hline \hline Time & \multicolumn{1}{c}{ Domain } & Center \\
\hline & Marine cyclone & \\
1200 UTC 18 January & $30^{\circ}-54^{\circ} \mathrm{N}, 80^{\circ}-50^{\circ} \mathrm{W}$ & $42^{\circ} \mathrm{N}, 65^{\circ} \mathrm{W}$ \\
0000 UTC 19 January & $30^{\circ}-54^{\circ} \mathrm{N}, 75^{\circ}-45^{\circ} \mathrm{W}$ & $42^{\circ} \mathrm{N}, 60^{\circ} \mathrm{W}$ \\
1200 UTC 19 January & $30^{\circ}-54^{\circ} \mathrm{N}, 70^{\circ}-40^{\circ} \mathrm{W}$ & $42^{\circ} \mathrm{N}, 55^{\circ} \mathrm{W}$ \\
& & \\
& Land cyclone & \\
1200 UTC 20 January & $26^{\circ}-50^{\circ} \mathrm{N}, 105^{\circ}-75^{\circ} \mathrm{W}$ & $34^{\circ} \mathrm{N}, 90^{\circ} \mathrm{W}$ \\
0000 UTC 21 January & $26^{\circ}-50^{\circ} \mathrm{N}, 100^{\circ}-70^{\circ} \mathrm{W}$ & $34^{\circ} \mathrm{N}, 85^{\circ} \mathrm{W}$ \\
1200 UTC 21 January & $26^{\circ}-50^{\circ} \mathrm{N}, 95^{\circ}-65^{\circ} \mathrm{W}$ & $38^{\circ} \mathrm{N}, 80^{\circ} \mathrm{W}$ \\
\hline
\end{tabular}


$950 \mathrm{mb}$. This parameter provides a diagnostic quantity that is directly related to the central pressure and the pressure distribution within the cyclone system studied. The 950-mb level was chosen because it is an isobaric level that is everywhere above the ground at all map times within the region of study, but is sufficiently close to the surface to be representative of surface cyclogenesis. Note the close comparability of sea level pressure and the $950-\mathrm{mb}$ geostrophic relative vorticity discussed in section 4 and shown in Figs. 2a through $7 \mathrm{a}$.

In this paper, we are interested in diagnosing the synoptic-scale processes responsible for development and in including in the diagnosis the influence of all levels of the atmosphere above the surface. To accomplish this, an equation developed by Zwack and Okossi (1986) is used. Originally developed by Zwack and
Okossi in quasigeostrophic form, the following describes the development of the equation in a generalized form. The height $z$ of some arbitrary pressure level $p$ can be related to the height $z_{l}$ of the $950-\mathrm{mb}$ level $p_{l}$ by integrating the hydrostatic balance equation and substituting for density using the equation of state to obtain

$$
g z=g z_{l}+R \int_{p}^{p_{l}} T \frac{d p}{p}
$$

where $T$ is the temperature, $R$ the dry-air gas constant, and $g$ the acceleration due to gravity $\left(9.8 \mathrm{~m} \mathrm{~s}^{-2}\right)$. The geostrophic relative vorticity $\left(\zeta_{g}\right.$ or $\left.\zeta_{\mathrm{gl}}\right)$ is obtained by taking the Laplacian of (1) and dividing through by the Coriolis parameter $f$, resulting in
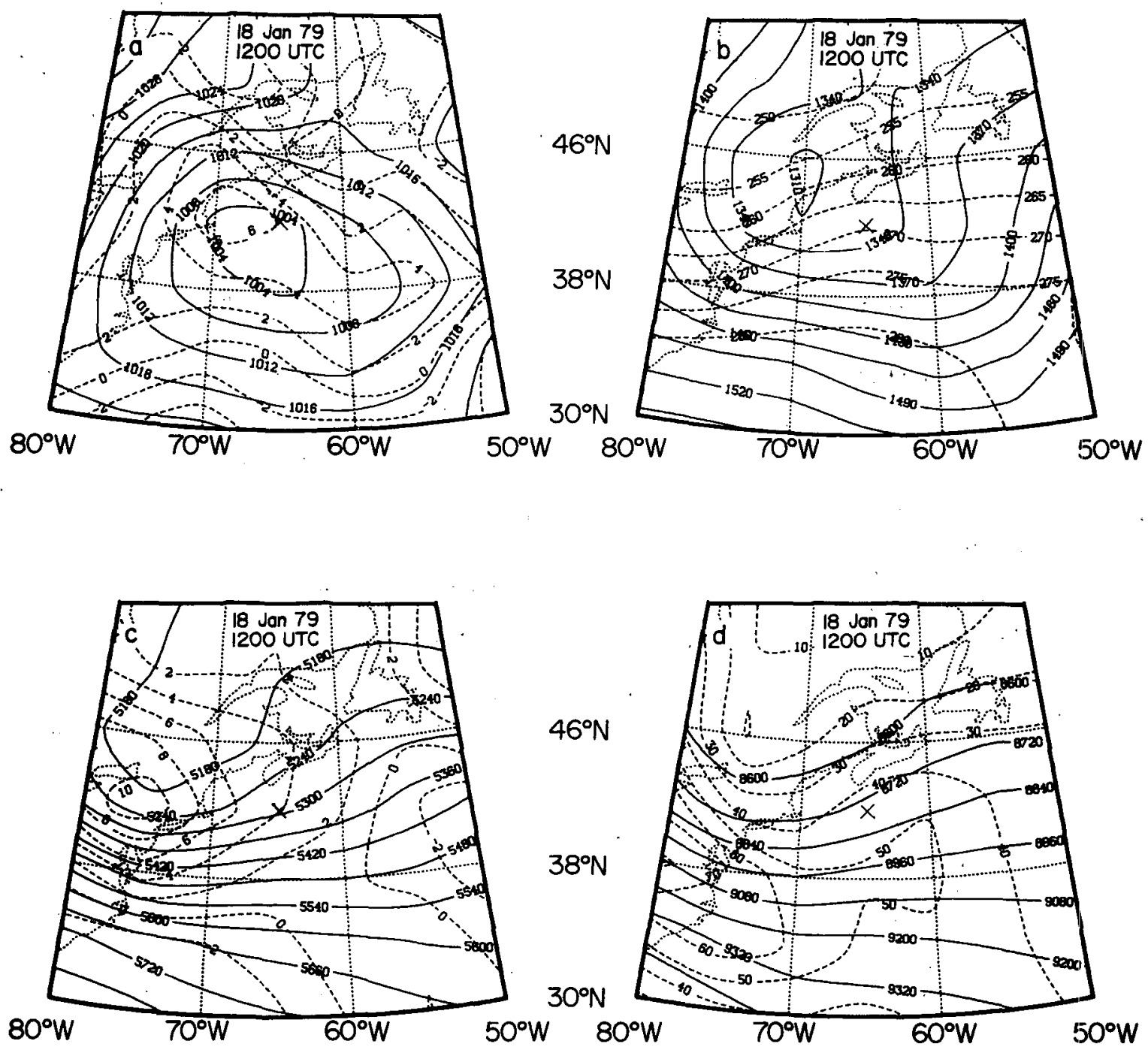

FIG. 2. Observed (a) $950-\mathrm{mb}$ geostrophic relative vorticity $\left(2 \times 10^{-5} \mathrm{~s}^{-1}\right.$, dashed) and sea level pressure (4 mb, solid), (b) 850 -mb heights $(30 \mathrm{~m}$, solid $)$ and temperatures $(5 \mathrm{~K}$, dashed $)$, (c) 500 -mb heights $\left(60 \mathrm{~m}\right.$, solid) and relative vorticity $\left(2 \times 10^{-5} \mathrm{~s}^{-1}\right.$, dashed), and (d) 300-mb heights (120 m, solid) and wind speed (10 $\mathrm{m} \mathrm{s}^{-1}$, dashed) for 1200 UTC 18 January 1979. The " $\times$ " denotes the grid point with minimum sea level pressure. 


$$
\frac{g}{f} \nabla^{2} z=\frac{g}{f} \nabla^{2} z_{l}+\frac{R}{f} \int_{p}^{p_{l}} \nabla^{2} T \frac{d p}{p} .
$$

Taking the partial derivative of (2) with respect to time, the geostrophic vorticity tendency can be obtained as

$$
\frac{\partial \zeta_{g}}{\partial t}=\frac{\partial \zeta_{\mathrm{gl}}}{\partial t}+\frac{R}{f} \int_{p}^{p_{l}} \nabla^{2} \frac{\partial T}{\partial t} \frac{d p}{p} .
$$

The geostrophic vorticity tendency can now be represented in terms of the actual vorticity $(\zeta)$ tendency by partitioning the latter quantity according to

$$
\frac{\partial \zeta}{\partial t}=\frac{\partial \zeta_{g}}{\partial t}-\frac{g}{f} \beta \frac{\partial}{\partial y}\left(\frac{\partial z}{\partial t}\right)+\frac{\partial \zeta_{\mathrm{ag}}}{\partial t},
$$

where $\beta=\partial f / \partial y$ and $\zeta_{\mathrm{ag}}$ is the ageostrophic vorticity $\left[\zeta_{\mathrm{ag}}=\zeta-\zeta_{g}+(g / f) \beta(\partial z / \partial y)\right]$. Substituting (4) into the vorticity equation, neglecting the $\beta$ term because it is an order of magnitude smaller, and solving for $\partial \zeta_{g} / \partial t$ yields

$$
\begin{aligned}
& \frac{\partial \zeta_{g}}{\partial t}=-\mathbf{V} \cdot \nabla \zeta_{a}+\zeta_{a} \frac{\partial \omega}{\partial p}-\left(\frac{\partial \omega \partial v}{\partial x \partial p}-\frac{\partial \omega \partial u}{\partial y \partial p}\right) \\
& -\omega \frac{\partial \zeta_{a}}{\partial p}+\mathbf{k} \cdot \nabla \times \mathbf{F}-\frac{\partial \zeta_{\mathrm{ag}}}{\partial t},
\end{aligned}
$$
(d)
(e)

(f)

where $\omega$ is the vertical motion in isobaric coordinates $(\omega=d p / d t), \mathbf{V}$ the horizontal wind vector with components $u$ and $v, \zeta_{a}$ the absolute vorticity $(\zeta+f)$, and $\mathbf{F}$ the frictional force. The right-hand-side terms, corresponding to quantities forcing changes in $\zeta_{g}$, are (a) horizontal vorticity advection, (b) the divergence effect in which $-\nabla \cdot V$ has been replaced by $\partial \omega / \partial p$ using the
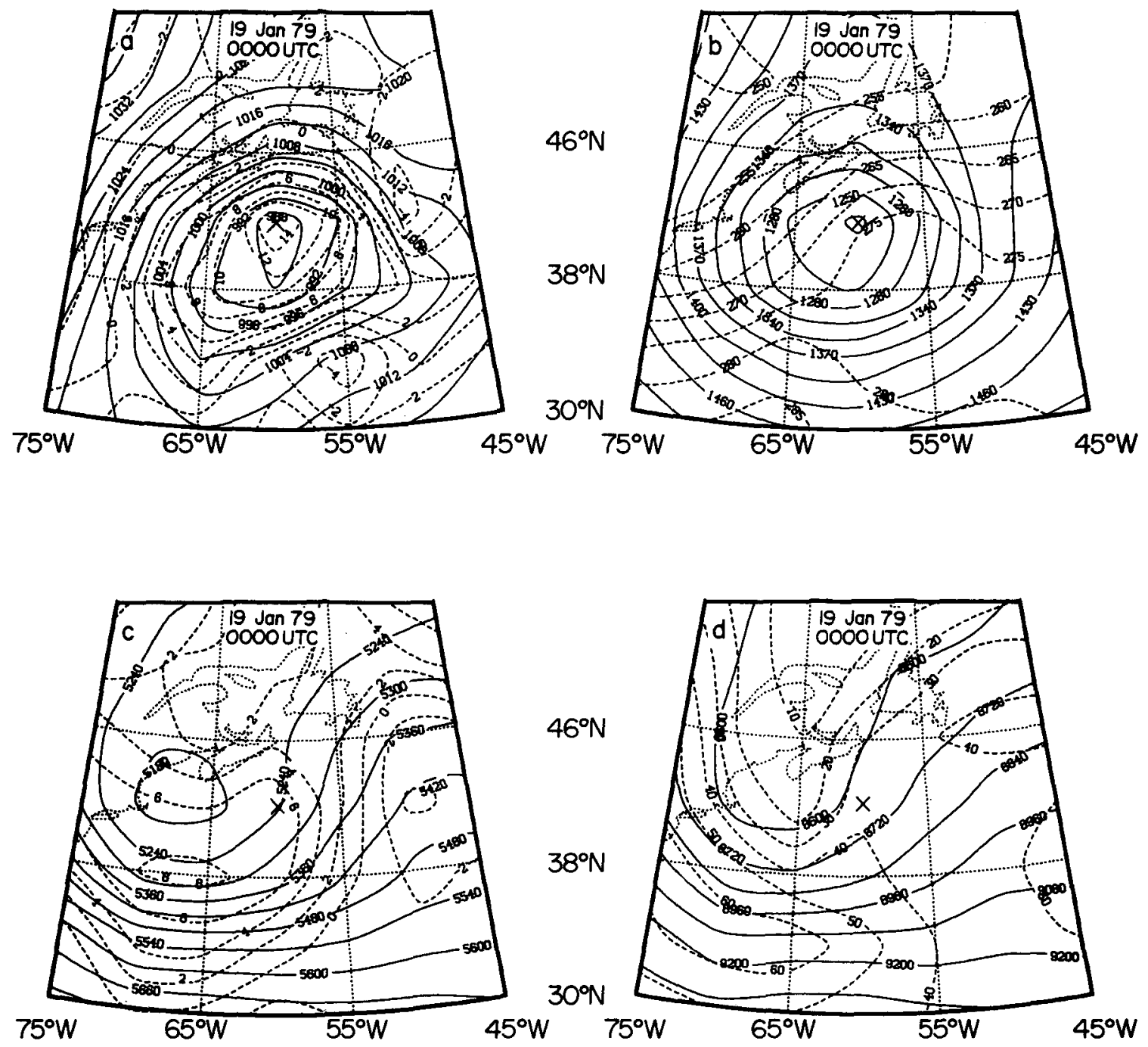

FIG. 3. As in Fig. 2, for 0000 UTC 19 January 1979. 
equation of continuity, (c) the tilting effect, (d) the vertical vorticity advection, (e) the frictional effect, and (f) the ageostrophic vorticity tendency.

The forcing responsible for the temperature tendency can be included by applying the first law of thermodynamics in the form

$$
\frac{\partial T}{\partial t}=-\mathbf{V} \cdot \nabla T+\frac{\dot{Q}}{c_{p}}+S \omega
$$

$$
\text { (a) (b) (c) }
$$

where $\dot{Q}$ is the diabatic heating rate per unit mass, $c_{p}$ the specific heat at constant pressure, and $S$ the static stability parameter. The parameter $S$ is given by

$$
S=-\frac{T}{\theta} \frac{\partial \theta}{\partial p}
$$

where $\theta$ is the potential temperature. Terms (a) and (c) in (6) represent the influence on the temperature change of horizontal temperature advection and adiabatic cooling and warming, respectively, while term (b) represents the influence of diabatic processes.

Substituting (5) and (6) into (3) and solving for $\partial \zeta_{\mathrm{gl}} / \partial t$ yields

$$
\frac{\partial \zeta_{\mathrm{gl}}}{\partial t}=-\mathbf{V} \cdot \nabla \zeta_{a}-\frac{R}{f} \int_{p}^{p_{l}} \nabla^{2}\left(-\mathbf{V} \cdot \nabla T+\frac{\dot{Q}}{c_{p}}+S \omega\right) \frac{d p}{p}
$$

(A)

(B) (C) (D)

$$
\begin{aligned}
& +\mathbf{k} \cdot \nabla \times \mathbf{F}-\frac{\partial \zeta_{\mathrm{ag}}}{\partial t}-\omega \frac{\partial \zeta_{a}}{\partial p} \\
& \text { (E) (F) (G) } \\
& -\left(\frac{\partial \omega \partial v}{\partial x \partial p}-\frac{\partial \omega \partial u}{\partial y \partial p}\right)+\zeta_{a} \frac{\partial \omega}{\partial p} \text {. }
\end{aligned}
$$

(H)

This expression now contains the explicit contributions
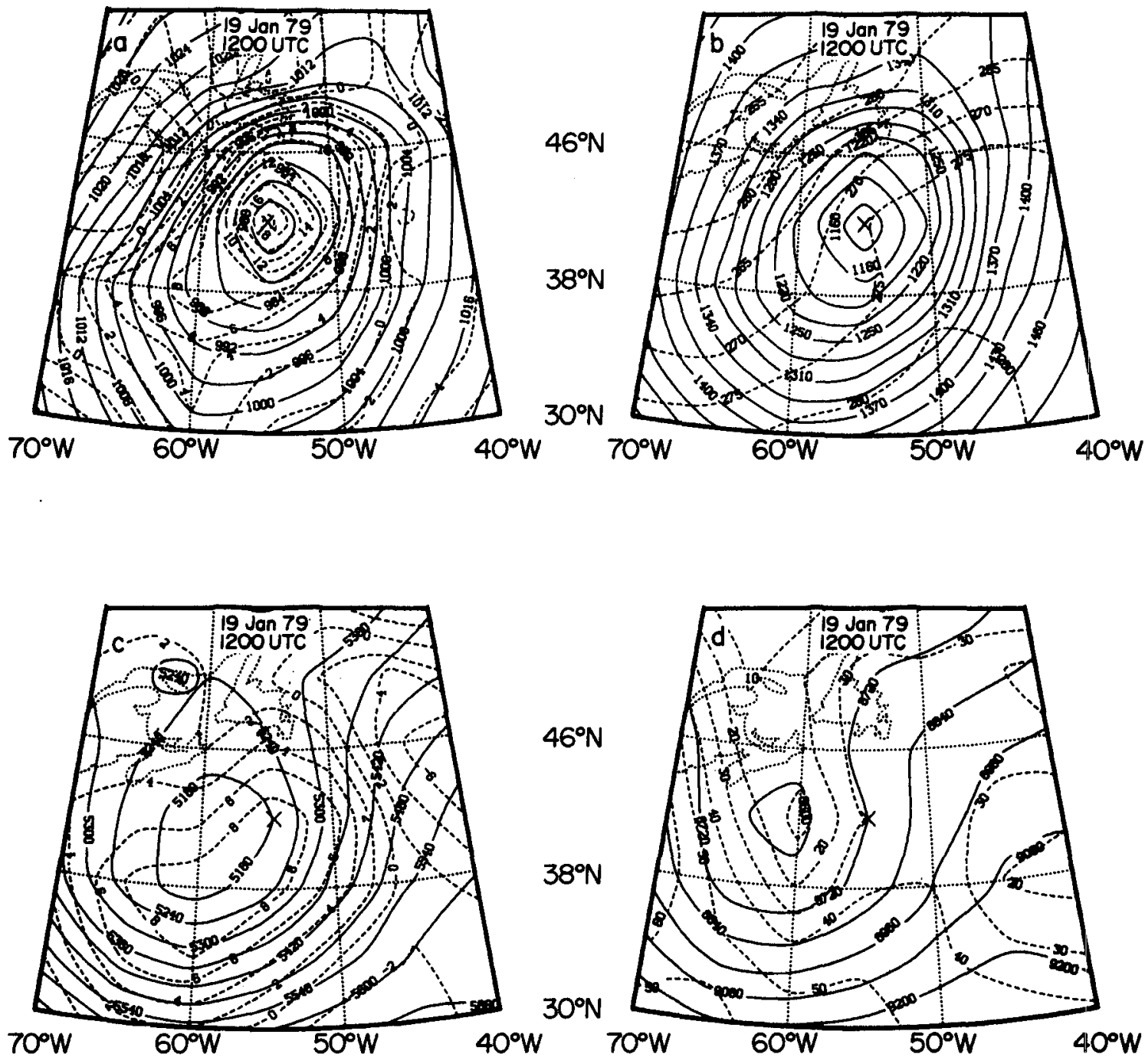

FIG. 4. As in Fig. 2, for 1200 UTC 19 January 1979. 
of an arbitrary pressure level $p$ to the geostrophic vorticity changes at $950 \mathrm{mb}$, with contributions from all other levels of the atmosphere included only implicitly. To explicitly include all levels, integrate $(8)$ from $p_{l}$ to a sufficiently high upper level $\left(p_{t}=100 \mathrm{mb}\right.$ in this study) and divide by the total pressure interval $\left(p_{l}-p_{t}\right)$ to obtain

$\frac{\partial \zeta_{\mathrm{gl}}}{\partial t}=\mathbf{P d} \int_{p_{t}}^{p_{l}}-\mathbf{V} \cdot \nabla \zeta_{a} d p-\mathrm{Pd}$

(A)

$\times \int_{p_{l}}^{p_{l}}\left[\frac{R}{f} \int_{p}^{p_{l}} \nabla^{2}\left(-\mathbf{V} \cdot \nabla T+\frac{\dot{Q}}{c_{p}}+S \omega\right) \frac{d p}{p}\right] d p$

(B)

(C)

(D)

$+\mathrm{Pd} \int_{p_{t}}^{p_{l}} \mathbf{k} \cdot \nabla \times \mathbf{F} d p-\mathrm{Pd} \int_{p_{t}}^{p_{l}} \frac{\partial \zeta_{\mathrm{ag}}}{\partial t} d p$

(E)

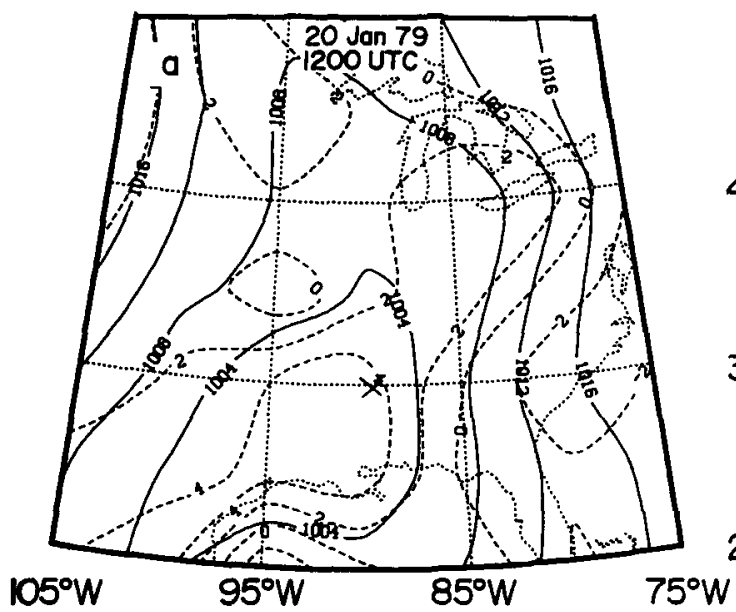

$-\operatorname{Pd} \int_{p_{t}}^{p_{t}} \omega \frac{\partial \zeta_{a}}{\partial p} d p-\operatorname{Pd} \int_{p_{t}}^{p_{l}}\left(\frac{\partial \omega \partial v}{\partial x \partial p}-\frac{\partial \omega \partial u}{\partial y \partial p}\right) d p$

(G)

$$
+\operatorname{Pd} \int_{p_{t}}^{p_{l}} \zeta_{a} \frac{\partial \omega}{\partial p} d p
$$

(I)

where $\mathrm{Pd}=\left(p_{l}-p_{t}\right)^{-1}$. This is the generalized $\mathrm{Z}-\mathrm{O}$ equation.

The processes represented by each of the terms in (9) are as given for (5) and (6). In all cases the terms lead to near-surface geostrophic vorticity tendencies by forcing divergence (convergence) at levels above $p_{l}$ and corresponding spatially varying height decreases (increases) at $p_{l}$. Terms $A, G$, and $H$ represent divergence (convergence) that is produced as the atmosphere readjusts to a spatially varying, geostrophically balanced state in response to locally increased (decreased)
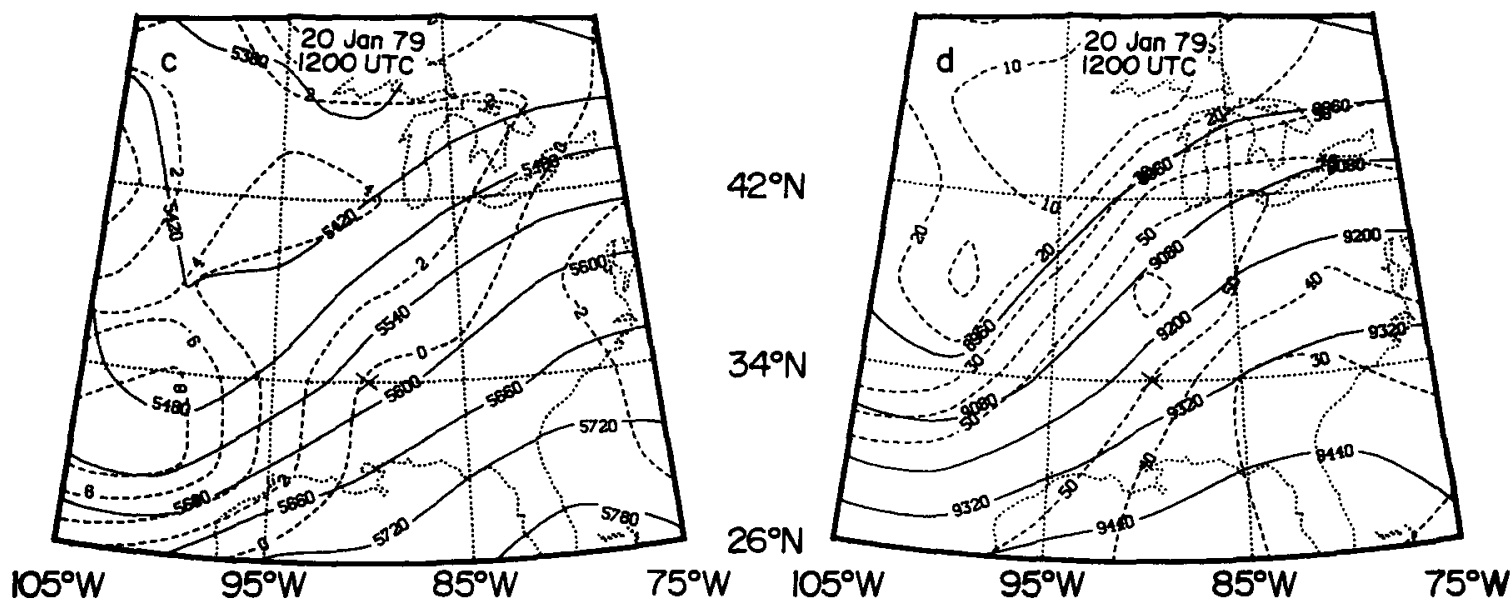

FlG. 5. As in Fig. 2, for 1200 UTC 20 January 1979. 
vorticity values. Terms $B, C$, and $D$ represent heating (cooling) processes that force horizontally nonuniform upward (downward) displacements of the height fields. This results again in local divergence (convergence) as the atmosphere attempts to reestablish a geostrophically balanced state. Term $F$ represents a correction term that accounts for the possibility that the imbalanced atmosphere may attempt to reach a balanced state other than geostrophic. Term E represents the divergence (convergence) caused by frictional effects and is most important in the planetary boundary layer. Finally, term I reflects the vertically integrated divergence left in place as the atmosphere adjusted to its current state. It should also be noted that the left-hand side of (9) and term $\mathrm{D}$ are interdependent. A discussion of how these two terms interact in a simple quasigeostrophic, analytic atmosphere can be found in Zwack and Okossi (1986, p. 664).

\section{b. Simplified forms of the Zwack-Okossi development equation}

The complete Z-O equation ( 9 ) includes, in principle, all of the physical processes responsible for development. However, it may be that some of the terms are operative on smaller time and space scales than represented by the data. In this case, attempts to retain them in the computations could result in aliasing errors. Thus, simplified versions of (9) are also examined.

The form of term I suggests that as a result of compensating convergence (divergence) features it should be small. Further, Tsou et al. (1987), in their analysis of the height tendency equation, suggest that terms G and $\mathrm{H}$ are small. Indeed, the calculations of these three terms show them to be consistently at least an order of magnitude smaller than terms A-D. Thus, the first simplified equation examined removes terms $\mathrm{G}-\mathrm{I}$ from
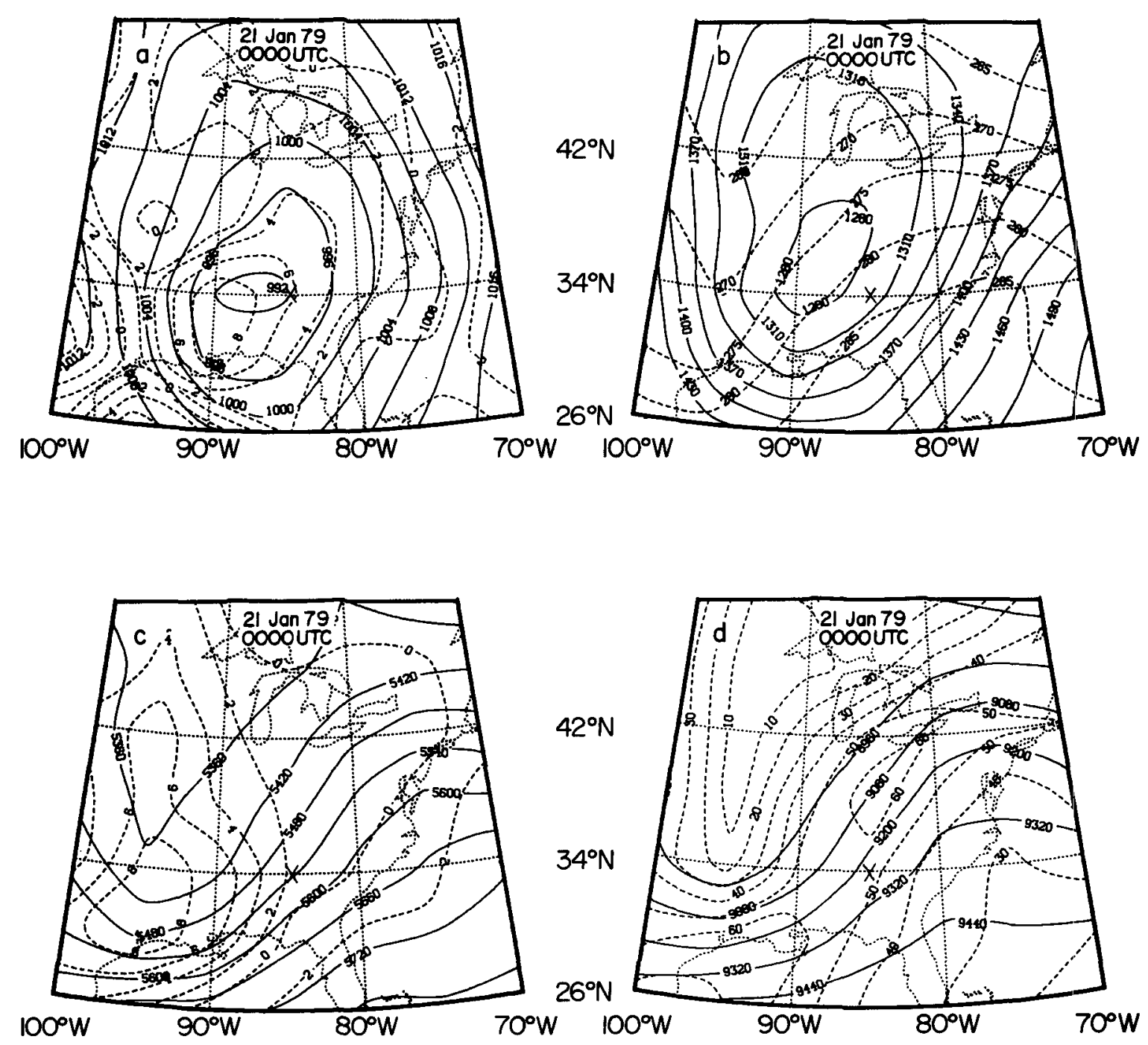

FIG. 6. As in Fig. 2, for 0000 UTC 21 January 1979. 
(9). This is known as the modified form (MOD) of the $\mathrm{Z}-\mathrm{O}$ equation

$$
\frac{\partial \zeta_{\mathrm{gl}}}{\partial t}=\mathbf{P d} \int_{p_{t}}^{p_{l}}-\mathbf{V} \cdot \nabla \zeta_{a} d p-\mathbf{P d}
$$

$$
\times \int_{p_{t}}^{p_{l}}\left[\frac{R}{f} \int_{p}^{p_{l}} \nabla^{2}\left(-\mathbf{V} \cdot \nabla T+\frac{\dot{Q}}{c_{p}}+S \omega\right) \frac{d p}{p}\right] d p
$$

(C) (D)

$$
+\operatorname{Pd} \int_{p_{t}}^{p_{l}} \mathbf{k} \cdot \nabla \times \mathbf{F} d p-\mathbf{P d} \int_{p_{t}}^{p_{l}} \frac{\partial \zeta_{\mathrm{ag}}}{\partial t} d p
$$

(E)

(F)

The results of Tsou et al. (1987) also suggest that the ageostrophic tendency may be small on synoptic time and space scales. Thus, a second simplified form of the $\mathrm{Z}-\mathrm{O}$ equation in which term $\mathrm{F}$ is also removed from (9) is examined. This simplest form of the $\mathrm{Z}-\mathrm{O}$ equation is

$$
\frac{\partial \zeta_{\mathrm{gl}}}{\partial t}=\mathbf{P d} \int_{p_{t}}^{p_{t}}-\mathbf{V} \cdot \nabla \zeta_{a} d p-\mathrm{Pd}
$$

$$
\begin{array}{r}
\times \int_{p_{t}}^{p_{t}}\left[\frac{R}{f} \int_{p}^{p_{l}} \nabla^{2}\left(-\mathbf{V} \cdot \nabla T+\frac{\dot{Q}}{c_{p}}+S \omega\right) \frac{d p}{p}\right] d p \\
\text { (B) } \quad \text { (C) (D) } \\
+\operatorname{Pd} \int_{p_{t}}^{p_{l}} \mathbf{k} \cdot \nabla \times \mathbf{F} d p, \quad(11)
\end{array}
$$

(E)

and is referred to as the extended (EXT) form in analogy to the simplified form of the height tendency equation used by Tsou et al. (1987).

In all three forms of the Z-O equation [(9), (10),
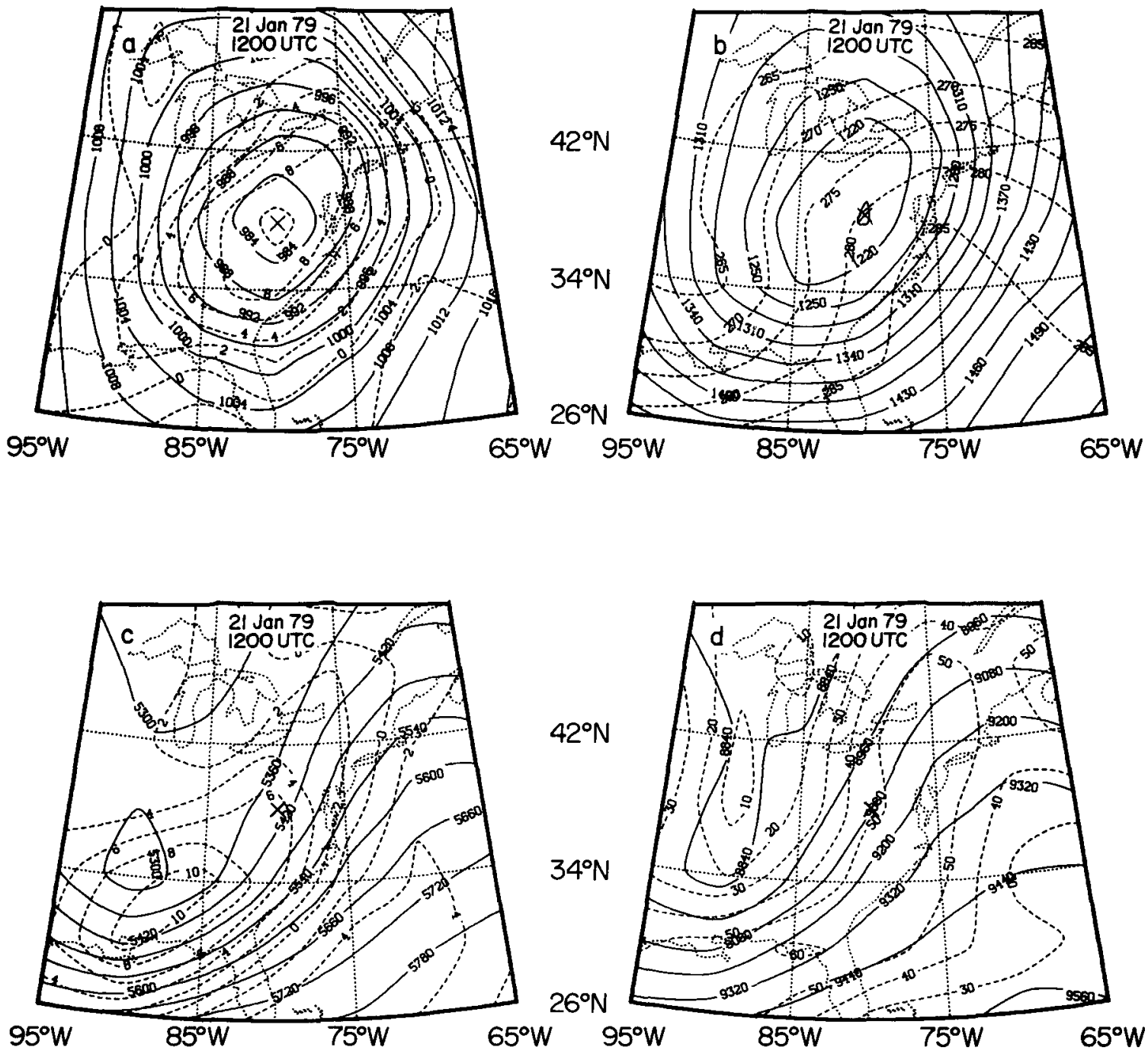

FIG. 7. As in Fig. 2, for 1200 UTC 21 January 1979. 
and (11)], term C includes two diabatic heating terms, latent heat release and boundary-layer sensible heating, referred to in later discussion as terms $\mathrm{C} 1$ and $\mathrm{C} 2$, respectively. In addition, a boundary-layer frictional influence is included. These terms, in addition to lowlevel large-scale advections and static stability, ensure that boundary-layer processes are represented in the $\mathrm{Z}-\mathrm{O}$ equation.
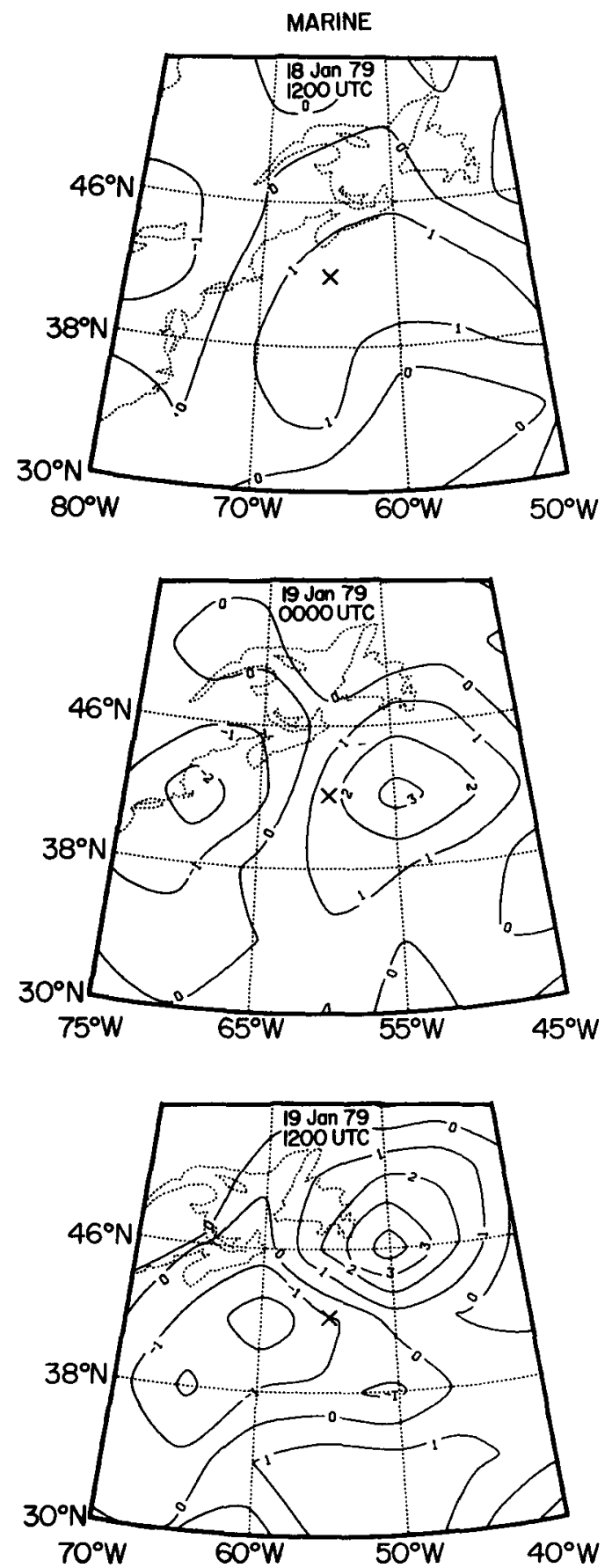

The reader will note that (11) bears marked similarity to the Petterssen-Sutcliffe (P-S) development equation (Petterssen 1956, pp. 320-325). However, the $\mathrm{Z}-\mathrm{O}$ equation is more complete than the P-S equation because, while the P-S equation explicitly takes into account only those processes occurring at and below the nondivergent level, the $\mathrm{Z}-\mathrm{O}$ equation explicitly accounts for the forcing processes at all levels
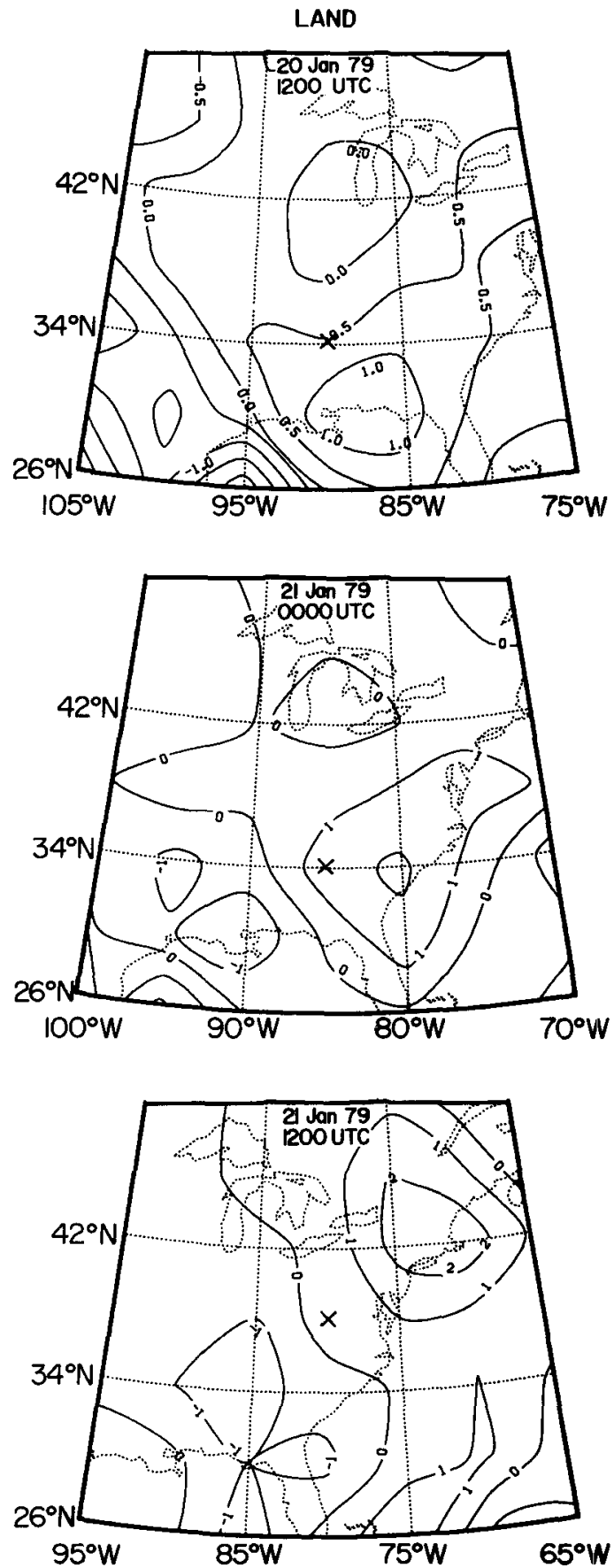

FIG. 8. Observed 950 -mb geostrophic relative vorticity tendencies $\left(10^{-9} \mathrm{~s}^{-2}\right)$ during the explosive development period for the marine cyclone (left) and land cyclone (right). The " $x$ " denotes the grid point with minimum sea level pressure. 
above the surface, thus fully exposing the extent of upper-air support responsible for low-level development.

\section{Computational methods}

\section{a. Data and finite differencing}

The dataset used in this research was the Goddard Laboratory for Atmospheres (GLA) 6-h interval special observation period I (SOP I) level IIIb analyses of the First GARP (Global Atmospheric Research Program) Global Experiment (FGGE) level IIb data (Baker 1983). The GLA objective analysis scheme is a fourdimensional data-assimilation procedure that results in a dynamically consistent blend of observational data and model forecast fields over a specified interval of time. This analysis scheme is a modification of the Cressman (1959) scheme, which involves successive
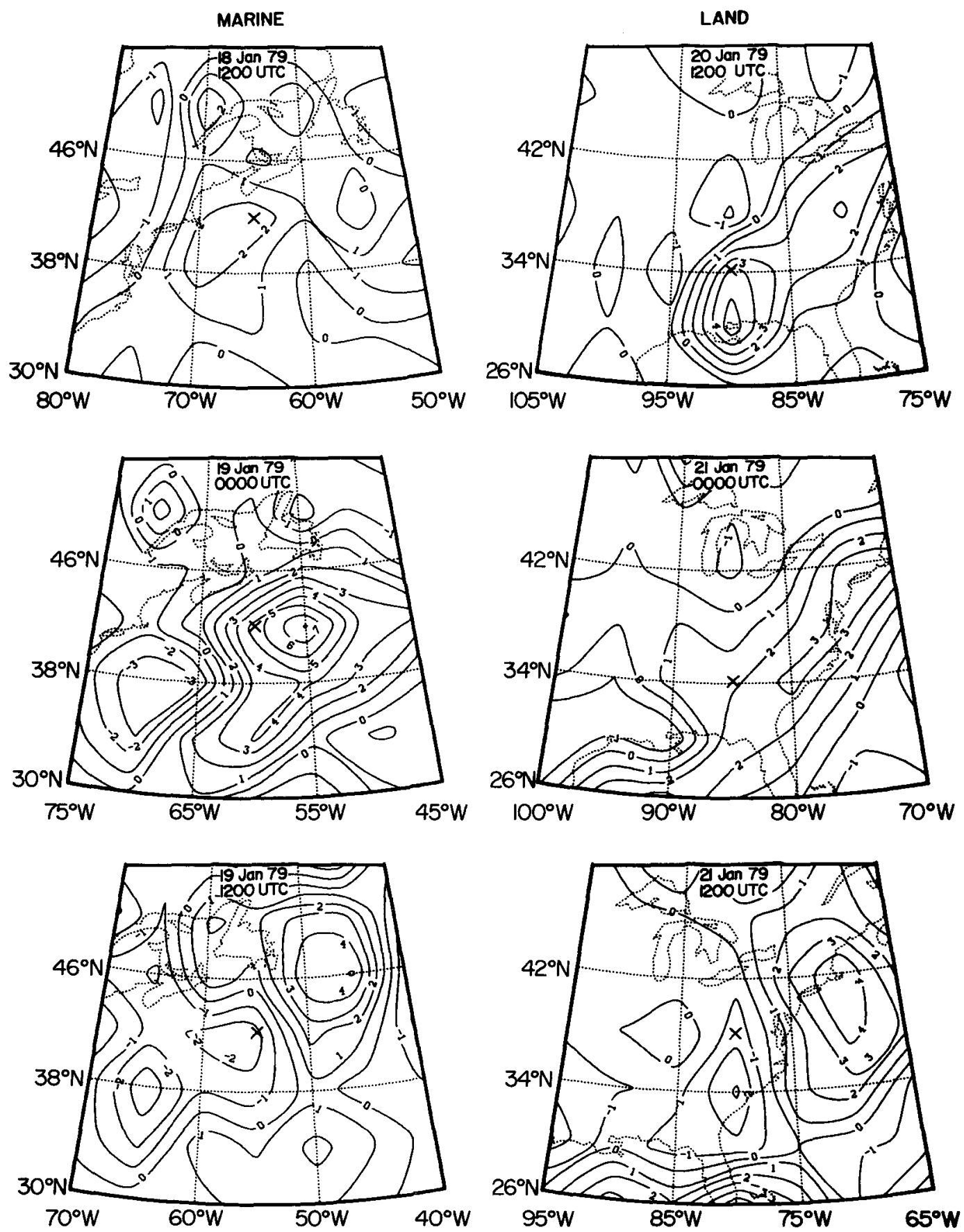

FIG. 9. As in Fig. 8, for 950-mb geostrophic relative vorticity tendencies $\left(10^{-9} \mathrm{~s}^{-2}\right)$ calculated using the total Zwack-Okossi equation. 
corrections to the first-guess fields modified to include variable data density and quality. The data-assimilation model used is the global fourth-order version of the GLA General Circulation Model (GCM) described in more detail in Kalnay-Rivas et al. (1977). This model consists of nine vertical levels in sigma coordinates with the horizontal grid scale of $4^{\circ}$ latitude $\times 5^{\circ}$ longitude. The FGGE IIb database contains mandatory pressure level data ( $1000-50 \mathrm{mb}$ ) derived from routine surface and upper-air observations, as well as aircraft reports, cloud-motion wind vectors from geostationary satellites, and temperature retrievals from the TIROS-N satellite. A complete discussion of the data analysis procedures is given in Baker (1983).

The computational domain used in this research is only a portion of the original global analyses done by the GLA GCM. Figure 1 shows the area of data coverage used in this research, extending from $22^{\circ}$ to $82^{\circ} \mathrm{N}$ and $0^{\circ}$ to $120^{\circ} \mathrm{W}$, covering nearly all of North America, the North Atlantic Ocean, and extreme western Europe and Africa. In the vertical, the data ranged from 1050 to $50 \mathrm{mb}$, interpolated or extrapolated to $50-\mathrm{mb}$ intervals.

In order to focus on the evolving cyclones, results presented here are restricted to moving domains extending over $24^{\circ}$ latitude and $30^{\circ}$ longitude. An example of this smaller domain for the marine cyclone at its first map time is outlined by dashed lines in Fig. 1. The lower boundary of the computational domain is $950 \mathrm{mb}$, as previously discussed, while the upper boundary is $100 \mathrm{mb}$. The $100-\mathrm{mb}$ level was chosen in order to include the entire troposphere and lower stratosphere in the diagnoses. Table 1.identifies the latitude and longitude limits of this area for each map time.

In calculating the $\mathrm{Z}-\mathrm{O}$ geostrophic vorticity tendencies, second-order finite differencing was used to evaluate all derivatives, while the trapezoidal rule was used for estimating vertical integrals. Also, the actual tendency quantities contain both a development and propagation component (Haltiner and Martin 1957, pp. 310-311). In order to isolate the development component, one needs to focus on a point within a propagating system at which the propagation component of the system is zero. For a closed pressure system, the center of the system is such a point. In this paper, the development component of the 950-mb geostrophic vorticity tendency was isolated by calculating averages over the nine grid points represented by the center of the cyclone and the eight grid points that surround the center point, referred to as nine-point averages (NPAs) in section 6.

\section{b. Diabatic heating and boundary-layer processes}

The latent heat release (LHR) estimates were obtained by first parameterizing the subgrid scale, or convective (CLHR), and grid scale, or stable (SLHR), components and summing them, and then modifying this sum using satellite infrared (IR) imagery in a technique described by Fosdick and Smith (1991). The CLHR component was estimated using the Kuo (1965, 1974) parameterization technique with modifications outlined by Edmon and Vincent (1976), Lin and Smith (1979), and Smith et al. (1984). The SLHR. component was obtained using the procedure of Krishnamurti and Moxim (1971) and Vincent et al. (1977) in which the grid-scale latent heat release is proportional to the vertical advection of saturation specific humidity. Fosdick and Smith (1991) compared the parameterized estimates of LHR to estimates acquired from GOES satellite IR imagery, the latter obtained using a technique developed by F. R. Robertson of NASA's Marshall Space Flight Center for midlatitude systems based on work done by Robertson (1985) and Miller and Vincent (1987). This algorithm takes into account cirrus cloud shields, separating them from the rain-producing clouds by considering IR brightness gradients. These IR-derived LHR estimates were used to modify the magnitude and horizontal distribution of the vertically integrated parameterized values. Thus, the final LHR values reflect the horizontal distribution and magnitude of the IR-derived fields and the vertical distribution of the parameterized fields.

The sensible heating rate was calculated using the surface sensible heat fluxes provided in the GLA dataset. The sensible heat flux was assumed to decrease linearly throughout the depth of the boundary layer and was set to zero at the fourth level above the surface. For all grid points within the computational domain this level was either 850 or $800 \mathrm{mb}$. The sensible heating rate was then determined as the divergence of the flux values.

The boundary-layer friction values were calculated using the algorithm derived by Krishnamurti (1968). The drag coefficient required in Krishnamurti's method was calculated using an algorithm taken from the GLA GCM (Kalnay et al. 1983). The drag coefficient within the boundary layer was assumed to decrease linearly with height and was set to zero at $850 \mathrm{mb}$.

TABLE 2. The 24-h-averaged mean absolute values (MAV) of 950 mb geostrophic vorticity tendencies and correlation coefficients $(\mathrm{CC})$ between $\mathrm{Z}-\mathrm{O}$ model and observed (OBS) tendencies. Values were calculated over the domains specified in Table 1. Designations TOT, MOD, and EXT refer to 950 -mb vorticity tendencies calculated from (9), (10), and (11), respectively.

\begin{tabular}{lcccc}
\hline \hline & \multicolumn{4}{c}{ MAV $\left(\times 10^{-9} \mathrm{~s}^{-2}\right)$} \\
\cline { 2 - 5 } & TOT & MOD & EXT & OBS \\
\hline Marine cycione & 1.425 & 1.464 & 1.220 & 0.805 \\
Land cyclone & 1.281 & 1.276 & 1.190 & 0.637 \\
& & & & \\
Marine cyclone & .730 & .728 & .594 & \\
Land cyclone & .557 & .533 & .507 & \\
\hline
\end{tabular}




\section{c. Comparison procedures}

The statistics used to compare calculated $\mathrm{Z}-\mathrm{O}$ geostrophic vorticity tendencies with observed geostrophic vorticity tendencies were correlation coefficients and mean absolute values. The correlation coefficients were calculated between geostrophic vorticity tendencies derived from the three different forms of the $\mathrm{Z}-\mathrm{O}$ equation [(9), (10), and (11)] and observed geostrophic vorticity tendencies determined as $12-\mathrm{h}$ finite differences of geostrophic vorticity centered on the appropriate time from $6 \mathrm{~h}$ before to $6 \mathrm{~h}$ after each map time. The mean absolute value is the mean of the absolute value of the vorticity tendencies over all grid points. These statistics were calculated for the smaller cyclone domains described earlier (see Table 1). These statistics were also averaged over the 24-h explosive development period (three map times) for each case.

\section{d. The omega equation}

The vertical velocities were calculated using the omega equation in the extended form as specified by Tsou and Smith (1990),

\section{MARINE}
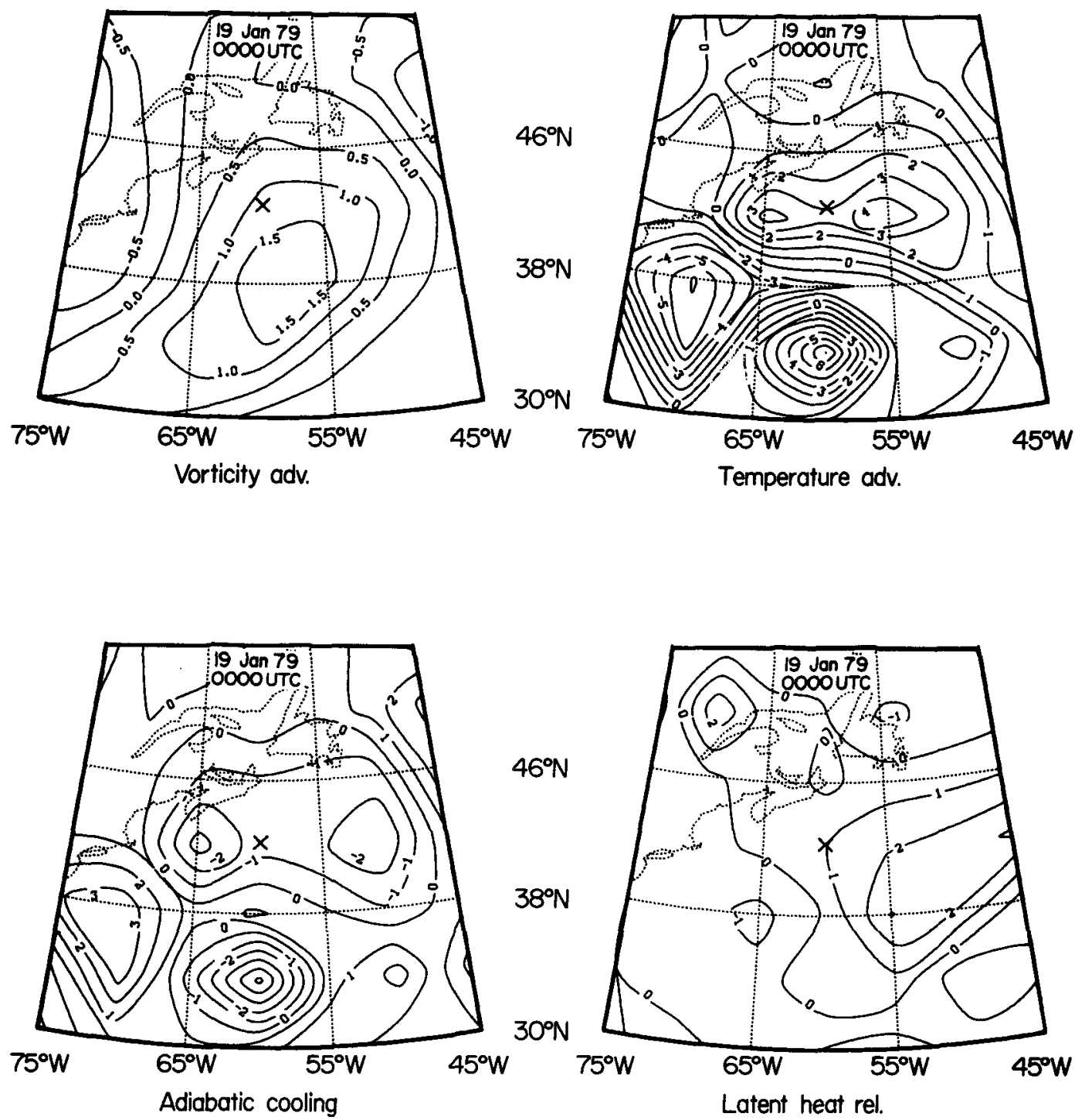

FIG. 10. Individual $950-\mathrm{mb}$ forcing contributions to the total calculated vorticity tendency $\left(10^{-9} \mathrm{~s}^{-2}\right)$ for the four largest terms on 0000 UTC 19 January 1979 (marine cyclone). The " $X$ " denotes the grid point with minimum sea level pressure. 


$$
\begin{aligned}
{\left[\nabla^{2} \sigma\right.} & \left.+f(\zeta+f) \frac{\partial^{2}}{\partial p^{2}}\right] \omega=f \frac{\partial}{\partial p}\left(\mathbf{V} \cdot \nabla \zeta_{a}\right) \\
+ & \frac{R}{p} \nabla^{2}(\mathbf{V} \cdot \nabla T)-\frac{R}{p} \nabla^{2}\left(\frac{\dot{Q}}{c_{p}}\right)+f \frac{\partial}{\partial p}(\mathbf{k} \cdot \nabla \times \mathbf{F}),
\end{aligned}
$$

where $\sigma$ is the static stability parameter $\sigma=-(R T /$ $p \theta)(\partial \theta / \partial p)$. Equation (12) was solved using sequential overrelaxation with zero vertical and lateral boundary conditions. The relaxation iteration was terminated when the absolute difference between two successive solutions of $\omega$ was less than $10^{-3} \mu \mathrm{b} \mathrm{s}^{-1}$ at all grid points. Grid points that were below the earth's surface were also assigned a value of zero.

\section{Synoptic discussion \\ a. The marine cyclone}

The marine case first appeared as a closed cyclone over the northern Great Plains at 1200 UTC 17 January (not shown) with a central sea level pressure of 1012 $\mathrm{mb}$. The cyclone moved eastward across the northern states, and $24 \mathrm{~h}$ later, at the beginning of the explosive phase, was located at $42^{\circ} \mathrm{N}$ just off the coast of southern New England, with a central pressure of $1002 \mathrm{mb}$ (Fig. $2 \mathrm{a})$. In the next $12 \mathrm{~h}$, by 0000 UTC 19 January, the cyclone moved due east along $42^{\circ} \mathrm{N}$ and deepened 17 $\mathrm{mb}$ to a central pressure of $985 \mathrm{mb}$ (Fig. 3a). By 1200 UTC 19 January (Fig. 4a), the end of the explosive development period, the cyclone's central pressure had
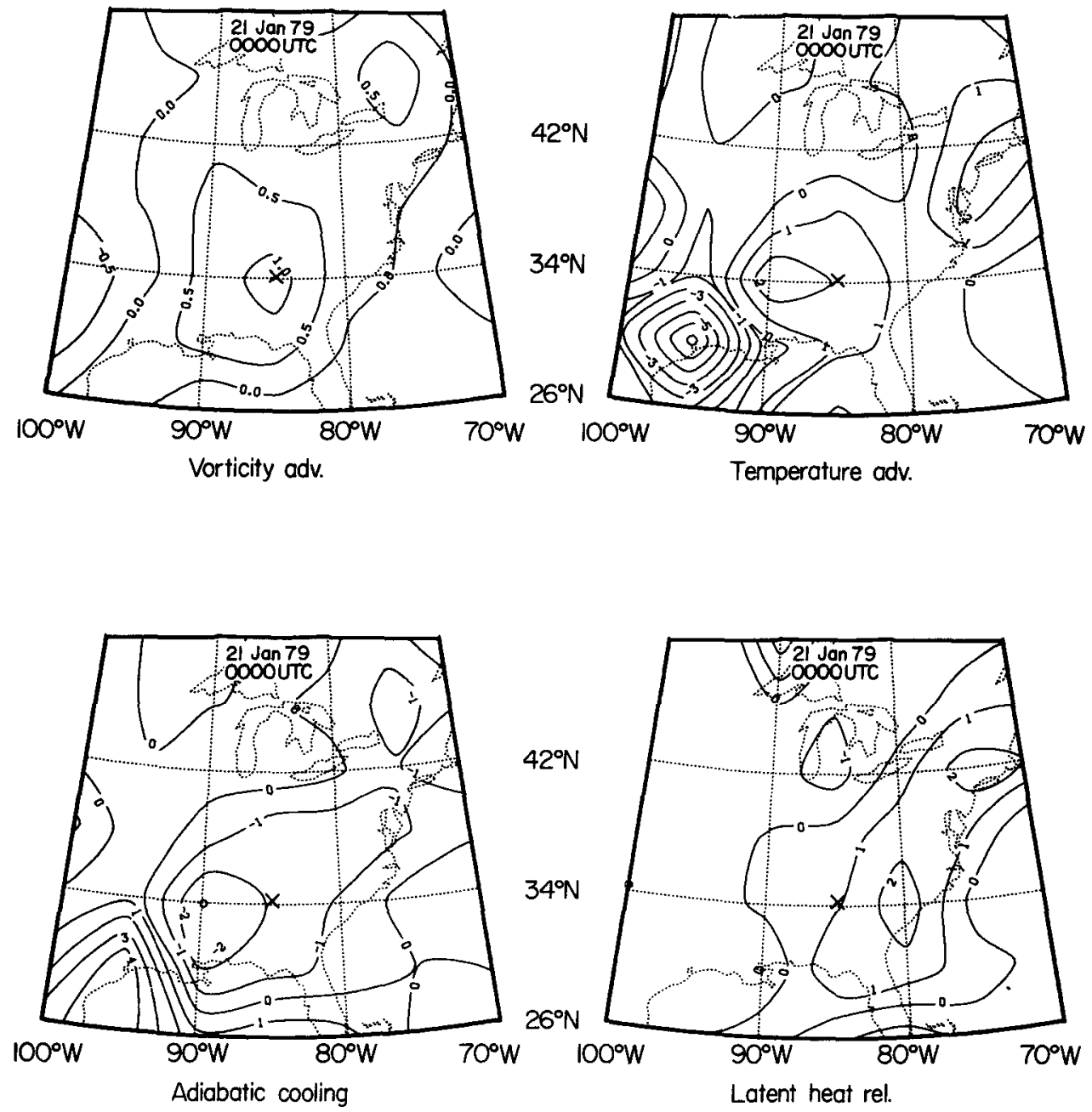

FIG. 11, As in Fig. 10, for 0000 UTC 21 January 1979 (land cyclone). 
dropped to $971 \mathrm{mb}$, yielding a total 24-h pressure fall of $31 \mathrm{mb}$, or 1.67 bergerons. The $950-\mathrm{mb}$ geostrophic relative vorticity patterns (Figs. 2-4a) mirror the sea level pressure patterns, with the vorticity maxima coincident with the sea level pressure minima. During the explosive development period the maximum 950mb geostrophic vorticity increased from about $7 \times 10^{-5}$ to $21 \times 10^{-5} \mathrm{~s}^{-1}$, reflecting the rapid cyclone intensification.

The $850-\mathrm{mb}$ trough (low) at 1200 UTC 18 January (Fig. 2b) was located over New England and southeastern Canada about $5^{\circ}$ longitude west of the surface system, with a minimum closed contour of $1310 \mathrm{~m}$. The $850-\mathrm{mb}$ temperature wave was about $90^{\circ}$ out of phase, suggesting a highly baroclinic system with coldair advection into and warm-air advection ahead of the trough. By 0000 UTC 19 January (Fig. 3b) the $850-\mathrm{mb}$ low, with a minimum contour down to $1220 \mathrm{~m}$, was located nearly over the surface cyclone. The temperature wave continued to lag the surface feature and exhibited stronger gradients. By the end of the explosive development period, the minimum contour in the $850-\mathrm{mb}$ low (Fig. 4b) had decreased to $1130 \mathrm{~m}$, giving a total 24-h height fall of $180 \mathrm{~m}$. The lowest height values at

MARINE/SMOOTHED
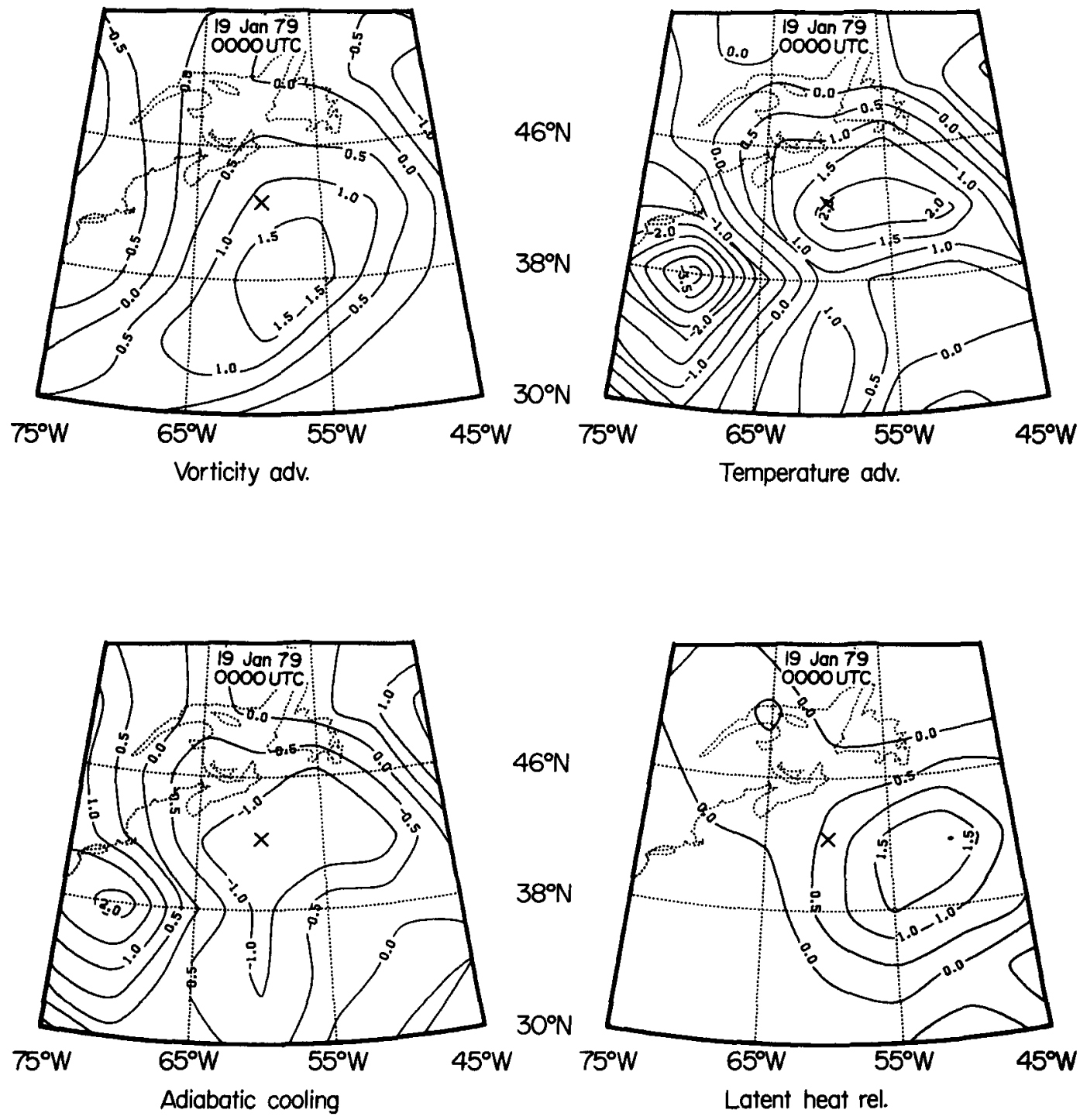

FIG. 12. As in Fig. 10, for 0000 UTC 19 January 1979 with the thermodynamic terms smoothed. 
this time were still nearly coincident with the center of the surface cyclone, and the $850-\mathrm{mb}$ temperature wave was still $90^{\circ}$ out of phase with the pressure wave. The amplitude of the thermal wave had increased, but the temperature gradients had relaxed somewhat compared to the previous two map times. The cold-air-warm-air advection couplet rotated cyclonically about the center of the cyclone through the explosive development in a fashion similar to that demonstrated by Rogers and Bosart (1986).

The $500-\mathrm{mb}$ trough (Figs. 2c-4c) lagged the surface system throughout the 24-h explosive development period. The surface cyclone was about $500 \mathrm{~km}$ downstream from the $500-\mathrm{mb}$ trough by the end of the explosive development period, a configuration that was suggested by Sanders and Gyakum (1980). During this time, the 500-mb trough amplified but experienced only a modest increase in its maximum relative vorticity (from $8 \times 10^{-5}$ to $10 \times 10^{-5} \mathrm{~s}^{-1}$ ). However, the area covered by the 8 contour increased significantly. The $500-\mathrm{mb}$ vorticity values and $24-\mathrm{h}$ vorticity changes noted here are weaker than those obtained by Manobianco (1989a). Using the European Centre for Medium-Range Forecasts (ECMWF) $1.875^{\circ} \times 1.875^{\circ}$

\section{LAND/SMOOTHED}
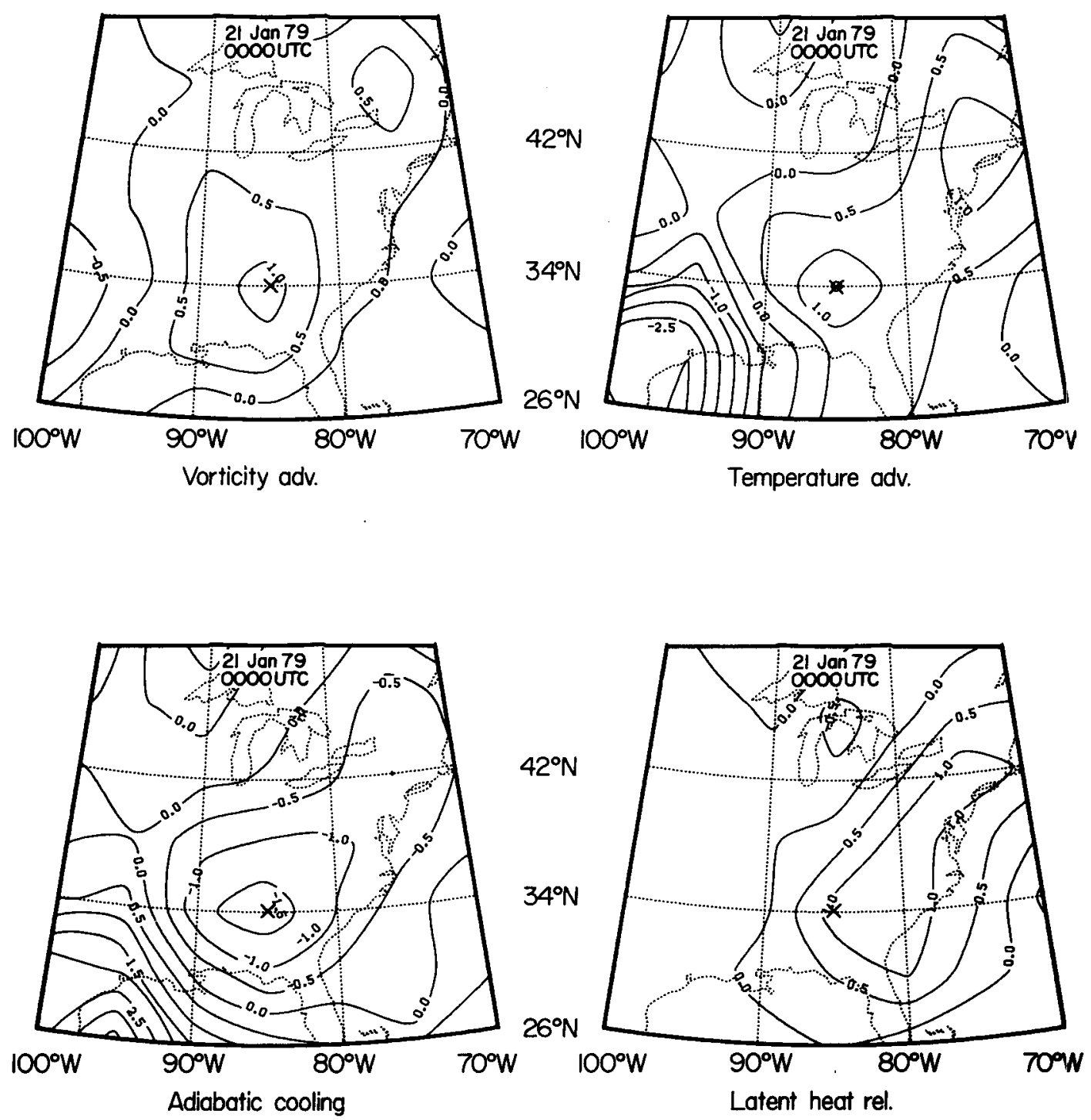

FIG. 13. As in Fig. 12, for 0000 UTC 21 January 1979. 
analyses, Manobianco found average relative vorticity changes from $13 \times 10^{-5}$ to $16 \times 10^{-5} \mathrm{~s}^{-1}$ during the first $24 \mathrm{~h}$ after explosive development commenced. Values were averaged for 24 explosive development cases of varying intensity. Differences in results likely reflect differences in the resolutions of the analyses used, with the higher resolution ECMWF analyses yielding larger vorticity values. As, noted in the Introduction, the analyses used here do not include the smaller-scale wave features likely to be captured in higher-resolution analyses. As a result, vorticities and other horizontal derivative quantities will be representative of the larger, synoptic-scale features diagnosed in this paper.

The $300-\mathrm{mb}$ trough positions were similar to those at $500 \mathrm{mb}$ and also experienced some amplification throughout the 24 -h period (Figs. $2 \mathrm{~d}-4 \mathrm{~d}$ ). Particularly notable at the first two map times was the position of the surface cyclone, which was located under diffluent flow at $300 \mathrm{mb}$ and was under the left-front region of the 300-mb jet maximum, the most favorable quadrant for surface development (Elsberry and Kirchoffer 1988). However, by 1200 UTC 19 January, the jet maximum, and consequently the left-front region, was displaced farther south of the surface cyclone.

\section{b. The land cyclone}

The land case first appeared as a closed cyclone at 1200 UTC 19 January 1979 (not shown) over the southwestern United States with a central sea level pressure of $1004 \mathrm{mb}$. At the beginning of the explosive development period on 1200 UTC 20 January the surface cyclone was located in the lower Mississippi Valley at a central pressure of $1000 \mathrm{mb}$ (Fig. 5a). The 950$\mathrm{mb}$ geostrophic relative vorticity maximum of 5 $\times 10^{-5} \mathrm{~s}^{-1}$ was coincident with the center of the cyclone. At 0000 UTC 21 January (Fig. 6a), the central pressure of the surface cyclone decreased to $992 \mathrm{mb}$ as the cyclone moved about $5^{\circ}$ longitude eastward. By 1200 UTC 21 January (Fig. 7a), as the cyclone moved northeastward into the mid-Atlantic region, the central pressure of the cyclone had fallen another $12 \mathrm{mb}$ to $980 \mathrm{mb}$. This is a 24-h pressure decrease of $20 \mathrm{mb}$, or 1.29 bergerons. The $950-\mathrm{mb}$ geostrophic vorticity maximum remained coincident with the area of lowest sea level pressure and doubled to about $10 \times 10^{-5} \mathrm{~s}^{-1}$ in the $24-\mathrm{h}$ period, again reflecting the rapid intensification.

The $850-\mathrm{mb}$ trough at 1200 UTC 20 January (Fig. $5 b)$ was located in the Great Plains and lagged the surface cyclone by about $5^{\circ}$. As in the marine case, the low-amplitude temperature wave lagged the $850-\mathrm{mb}$ low, yielding cold-air advection into and warm-air advection ahead of the trough. By 0000 UTC 21 January (Fig. 6b), the 850-mb low deepened to under $1280 \mathrm{~m}$, with the area of lowest heights located less than $5^{\circ}$ longitude west of the surface cyclone. The increased baroclinicity is indicated by the amplified temperature gradients. By 1200 UTC 21 January (Fig. 7b), the 850-mb low deepened to a minimum value of about $1190 \mathrm{~m}$, a 24-h decrease of $150 \mathrm{~m}$, and was located above the surface cyclone center. The thermal wave again intensified and continued to lag the $850-\mathrm{mb}$ trough. Also, as seen in the marine case, the cold-airwarm-air advection couplet rotated cyclonically around the center of the cyclone over the explosive development period (Rogers and Bosart 1986).

As for the marine case, the $500-\mathrm{mb}$ trough for the land case (Figs. $5 c-7 c$ ) remained to the west of the surface cyclone, amplified, and exhibited only modest increases in its maximum relative vorticity $\left(8.5 \times 10^{-5}\right.$ to $10 \times 10^{-5} \mathrm{~s}^{-1}$ ).

The 300-mb trough position was the same as that at $500 \mathrm{mb}$ throughout the period (Figs. $5 \mathrm{~d}-7 \mathrm{~d}$ ). The 300 $\mathrm{mb}$ trough deepened slightly but remained an open wave throughout the period. In contrast to the marine case, the land cyclone started the explosive development period on the anticyclonic side of the jet maximum and remained there until the last map time (Fig. 7d). However, even at this time the surface cyclone was not located directly beneath the left-front region of the jet maximum. Thus, during the entire period the surface cyclone was never in the most favorable position for development relative to the jet maximum. However, the surface cyclone was located beneath an area of 300-mb diffluent flow.

\section{Model and observed tendency comparisons}

The observed 12-h finite difference $950-\mathrm{mb}$ geostrophic vorticity tendencies for the marine and land cases are shown in Fig. 8. Examples of the corresponding model vorticity tendencies from the total $\mathrm{Z}-\mathrm{O}$ equation are shown in Fig. 9. In addition, Table 2 displays the corresponding 24-h averaged mean absolute values (MAV) and correlation coefficients (CC) for each case and for all three forms of the $\mathrm{Z}-\mathrm{O}$ equation.

As suggested by the $\mathrm{CC}$ values, although pattern variations are quite evident, there is general pattern comparability between the observed and all model fields. However, of particular concern at this point are the excessive magnitudes of the $\mathrm{Z}-\mathrm{O}$ fields. The $\mathrm{Z}-\mathrm{O}$ equation MAVs summarized in Table 2 are $50 \%-80 \%$

TABLE 3. As in Table 2 for calculations with smoothed thermodynamic terms.

\begin{tabular}{lcccc}
\hline \hline & \multicolumn{4}{c}{ MAV $\left(\times 10^{-9} \mathrm{~s}^{-2}\right)$} \\
\cline { 2 - 5 } & TOT & MOD & EXT & OBS \\
\hline Marine cyclone & 1.097 & 1.122 & 0.807 & 0.805 \\
Land cyclone & 0.906 & 0.867 & 0.732 & 0.637 \\
& & & & \\
Marine cyclone & .786 & .789 & .765 & \\
Land cyclone & .594 & .580 & .595 & \\
\hline
\end{tabular}


and $85 \%-100 \%$ larger than the observed vorticity tendencies for the marine and land cases, respectively. To examine this characteristic further, the four largest terms, the vorticity advection, temperature advection, static stability, and the latent heat release, are presented for the middle map time of each case in Figs. 10 and 11. Other map times showed similar features. If one compares the terms, it is apparent that the vorticity advection differs from the other three in two ways. First, the vorticity-advection tendencies are consistently smaller than the tendencies forced by the thermodynamic terms. Second, the vorticity-advection tendency term shows a smoother pattern consistent with the scale of the cyclone system being studied, while the thermodynamic terms exhibit much more pattern variability, especially in the areas of maxima and minima. This variability is about twice the scale of the grid $(2 \Delta x)$, and likely results from computational noise
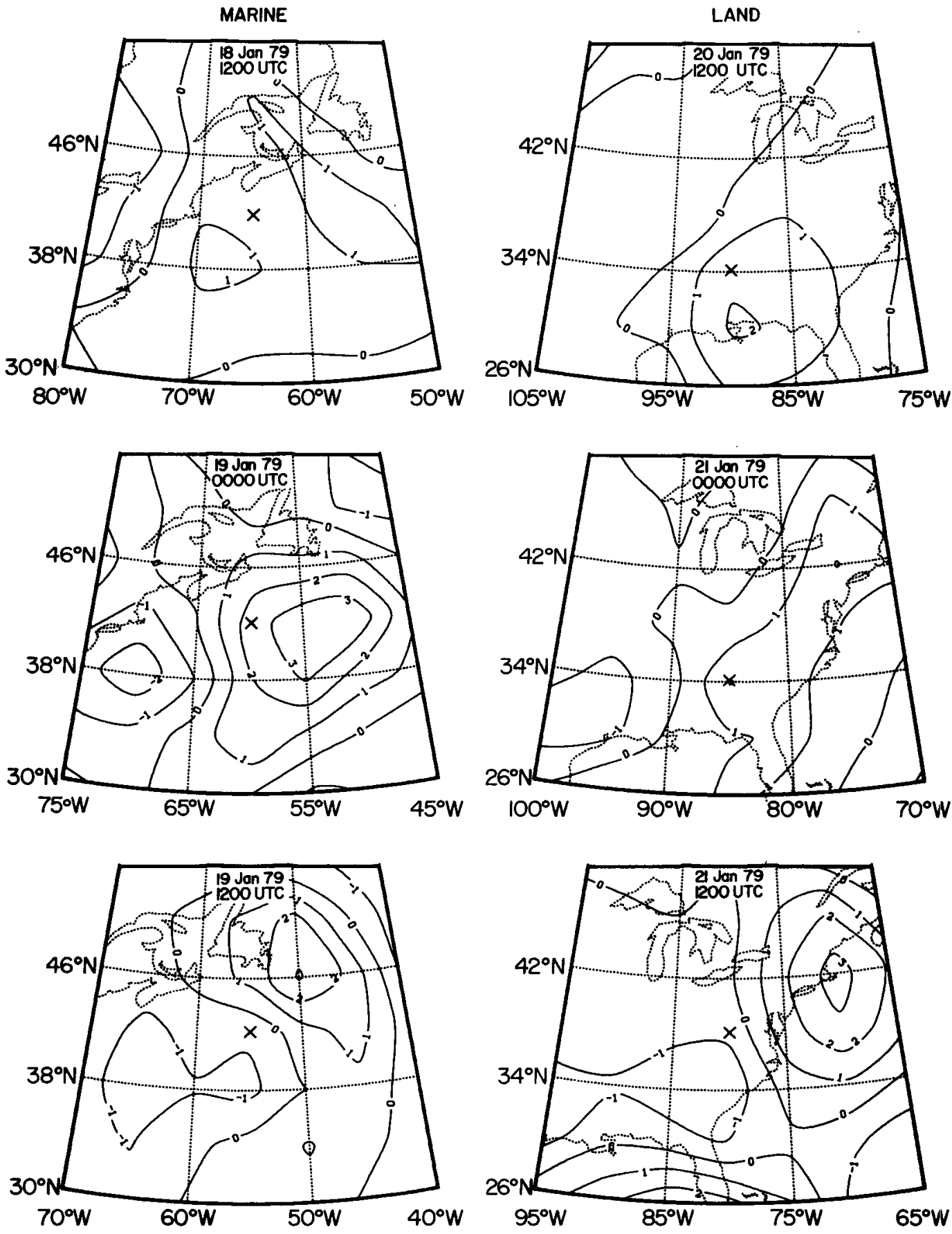

FiG. 14. As in Fig. 9, using the extended Zwack-Okossi equation with smoothed thermodynamic terms. 
induced by applying the Laplacian operator in each of the thermodynamic terms.

This noise feature and the excessive values seen in the maxima and minima suggest that a smoothing operation on the thermodynamic terms should be examined and that this smoothing should be accomplished over twice the grid interval. Thus, a simple smoothing was applied to the thermodynamic terms in which a smoothed tendency $t_{s}$ is given by

$$
t_{s}=\frac{\left(t_{c}+t_{1}+t_{2}+t_{3}+t_{4}\right)}{5.0},
$$

where $t_{c}$ is the original tendency at the grid point being smoothed and $t_{1}, t_{2}, t_{3}$, and $t_{4}$ are the original tenden-
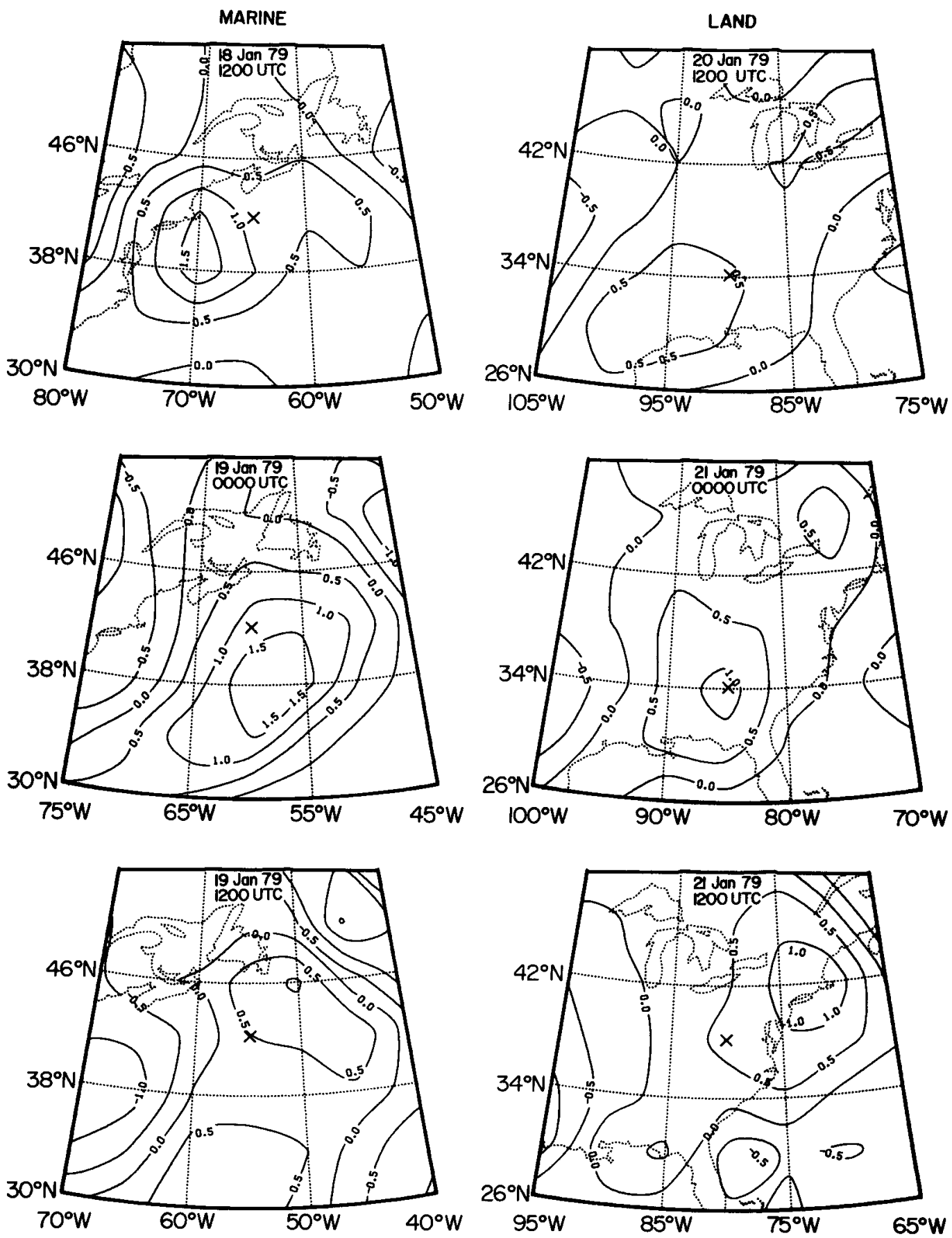

FIG. 15. Contribution to the total geostrophic vorticity tendency in Fig. 14 due to horizontal vorticity advection $\left(10^{-9} \mathrm{~s}^{-2}\right)$ for the marine cyclone (left) and land cyclone (right). The " $X$ " denotes the grid point with minimum sea level pressure. 
cies at the grid points immediately north, south, west, and east of the grid point being smoothed, respectively. The results of applying this technique, shown in Figs. 12 and 13, demonstrate, by comparing with Figs. 10 and 11 , that the $2 \Delta x$ smoother yields thermodynamic fields whose maxima and minima are reduced by $50 \%$. In addition, the patterns are smoothed to the point of greater scale similarity to the vorticity advection term. Thus, the smoothed fields appear to be a better rep- resentation of the forcing associated with the scale being studied.

If one examines the effect of the smoothing on the total vorticity tendencies (Table 3 ), it is clear that the MAVs for the smoothed $\mathrm{Z}-\mathrm{O}$ equation calculations are about $25 \%-30 \%$ smaller than the unsmoothed results. At the same time the correlation coefficients increased, with the greatest increase occurring in the extended Z-O tendencies. The smoothed total and
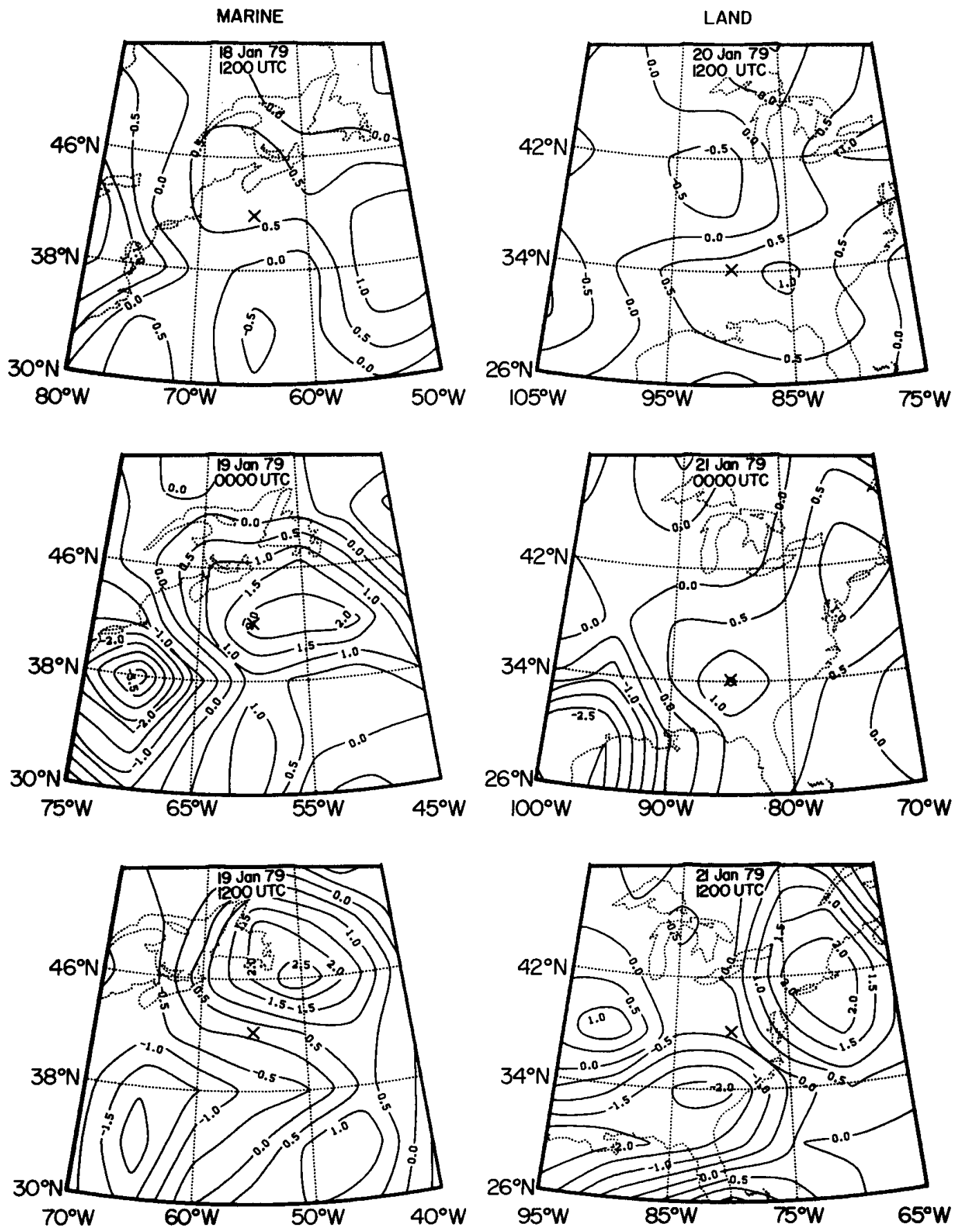

FIG. 16. As in Fig. 15, for the contribution due to horizontal temperature advection. 
modified tendencies, although moderated, remain significantly larger than the observed for both the marine and land cases. However, the smoothed extended tendencies are now much closer in magnitude to the observed and, further, exhibit correlations comparable to the other two forms. Thus, it is concluded that the smoothed, extended form of the Z-O equation provides the best model for diagnosing the cyclone system forcing on the time and space scales of the analysis fields used in this study. The failure of terms F-I in (9) to significantly improve the results suggest that they are operative on smaller time and space scales and, thus, could not be accurately calculated using these analysis fields.

Finally, the smoothed, extended Z-O equation total tendencies for both cases are displayed in Fig. 14. Comparing with Fig. 8, one can see that, in general, the patterns and magnitudes are quite similar. Note
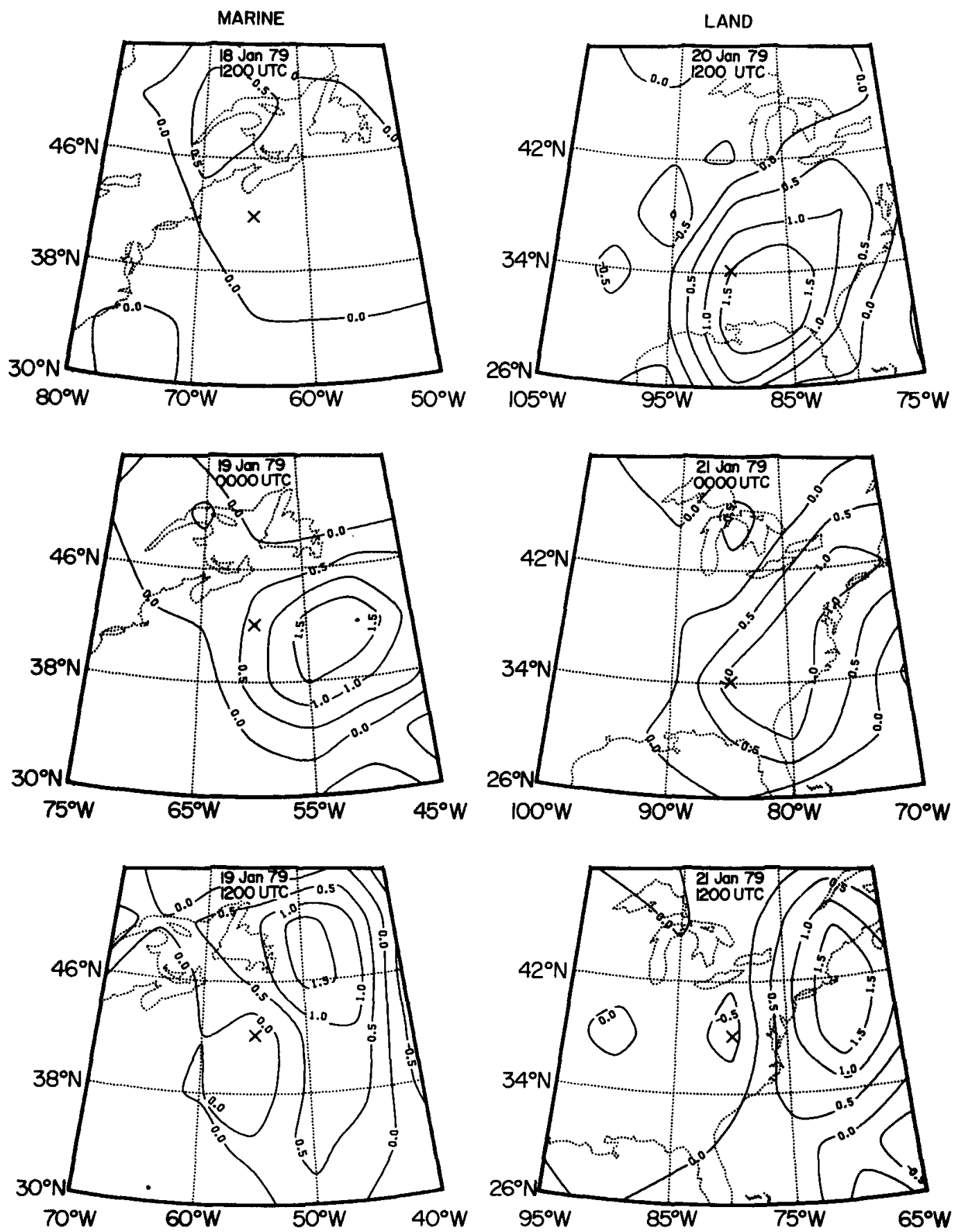

FIG. 17. As in Fig. 15, for the contribution due to latent heat release. 
that the similarity is particularly good in the areas of maximum cyclonic-vorticity tendencies. This point is important because of the implied reliability of the model vorticity tendencies in the cyclone region.

\section{Diagnostic results}

\section{a. Basic forcing processes}

At the beginning of explosive cyclogenesis for the marine case, the surface cyclone center was located
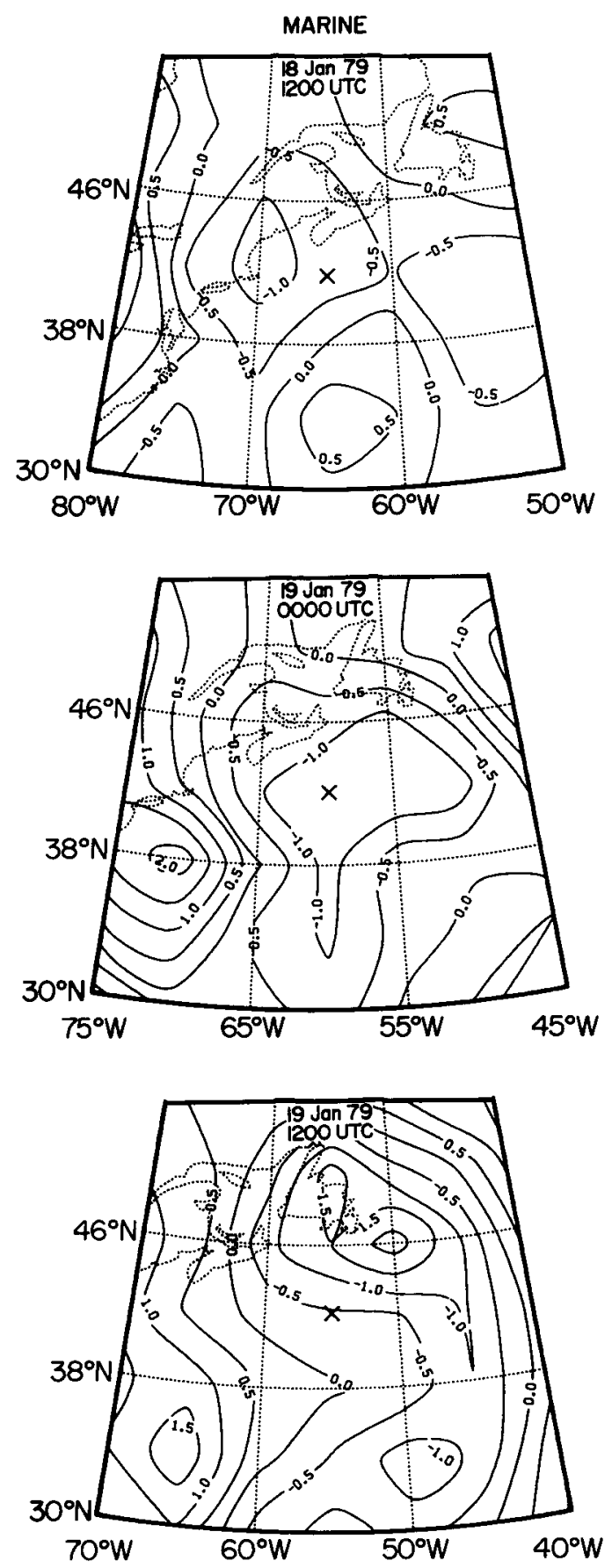

near the total tendency maximum (see Fig. 14). By the middle map time, the vorticity tendency maximum was located to the east of the surface cyclone and was stronger, with the cyclone remaining within the cyclonic-vorticity tendency area. However, by the final map time the cyclonic-vorticity tendency maximum had moved to the northeast of the cyclone, with negative tendencies now seen in the cyclone region. The land cyclone was also located well within positive tendency regions at the first two map times. By the final
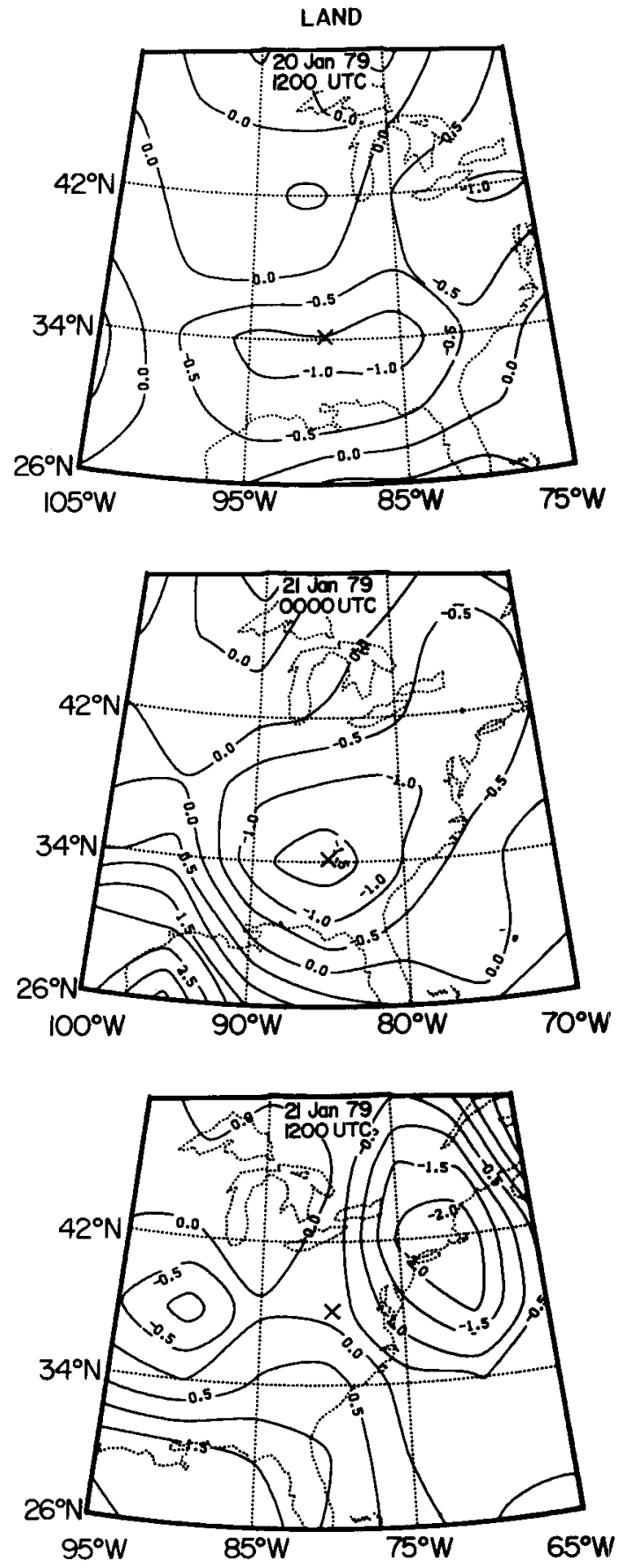

FIG. 18. As in Fig. 15, for the contribution due to adiabatic cooling. 
map time the cyclonic-vorticity tendencies reached their largest values but, as for the marine case, were located northeast of the surface cyclone, which was now located close to the zero tendency line. Note that for both cases development did not cease because the forcing processes diminished, but rather because the strong forcing moved downstream from the cyclones at the onset of occlusion.

The contribution of horizontal vorticity advection [term A in (11)] to the total vorticity tendency is displayed in Fig. 15. For both cases, the vorticity tendency maximum, associated with integrated cyclonic-vorticity advection, was located west of the surface cyclone at the beginning of the explosive development period. This maximum then passed over the cyclone centers near the middle map time and finally was located northeast of both cyclones at the end of the explosive development period, reflecting the eastward progression of the mid- and upper-tropospheric vorticity maxima relative to the surface cyclone as development ensued. The magnitude of the vorticity-advection maximum was greatest at the middle map time for the marine case and the last map time for the land case.

The contribution to the total vorticity tendency from the integrated horizontal temperature advection [term $B$ in (11)] is shown in Fig. 16. A positive contribution center, forced by integrated warm-air advection, was located nearly over the center of the surface cyclone for both cases at the first two map times. The final map time for the marine case showed a maximum contribution north of the surface cyclone, while for the land cyclone the maximum was northeast of the surface cyclone. For both cases, the maximum forcing due to horizontal temperature advection was largest at the final map time. In comparing the magnitude of the maximum forcing due to horizontal temperature advection to that attributed to vorticity advection, the magnitudes were similar at the first map time for both cases, but by the middle and final map times the temperature-advection term was about twice as large as the vorticity-advection term.

The contribution to the total vorticity tendency by the latent heat release [term $\mathrm{C} 1$ in (11)] is shown in Fig. 17. For the marine case the maximum contribution made by this term was largest at the middle map time, while for the land case the maximum contribution was largest at the final map time. With the exception of the first map time of the marine case, the maximum forcing due to latent heat release was slightly larger than the maximum of the vorticity-advection term. The center of the integrated maximum contribution due to latent heat release for the marine case was located to the north of the cyclone for the first map time, east of the cyclone for the middle map time, and northeast of the center at the final map time. The center of maximum contribution in the land case was located to the southeast of the center of the cyclone at the beginning of the explosive development period and rotated cyclonically to the northeast of the cyclone by the final map time.
In both cases, the maximum contribution due to latent heating became more detached from the center of the cyclone with time. This was confirmed by examining color-enhanced satellite imagery (not shown), which showed the deepest cloud layers northeast and east and farthest from the center at the final map time in both cases. These observations also agree with those of Gyakum (1983a) in his analysis of the $Q E I I$ storm.

The contribution to the total vorticity tendency due to adiabatic cooling and warming [term $D$ in (11)] is shown in Fig. 18. Clearly, the adiabatic-cooling term almost always operates in the opposite sense to the sum of the other principle forcing terms. To further examine the relationship between this term and the development terms, correlation coefficients were calculated between term D and terms $\mathrm{A}, \mathrm{B}$, and $\mathrm{Cl}$ (Table 4 ). For both cyclone cases the correlations were negative between the adiabatic-cooling term and each of the other three terms. Thus, the adiabatic-cooling (warming) induced in the upward (downward) vertical motions tends to offset the effect of each of the other terms in both cases. However, in general, the inhibiting effect of this term was not enough to completely neutralize the three positive development terms combined. The adiabatic cooling is best correlated with the temperature-advection term because the latter is the term that forces the majority of the upward motion.

The contribution to the total vorticity tendency by friction [term $E$ in (11)] and sensible heating [term $\mathrm{C} 2$ in (11)] are shown in Figs. 19 and 20, respectively. The frictional forcing (Fig. 19) was largest at the final map time and largest near the center of the cyclone for all map times in both cases. This term, which forced decreases in geostrophic vorticity, was larger for the marine cyclone, reflecting the stronger winds associated with this more intense case. The sensible heating (Fig. 20) made no significant contribution to the development of the cyclone in either the marine or land case,

TABLE 4. Correlations of geostrophic vorticity tendency forced by the adiabatic-cooling term versus that forced by the vorticityadvection, temperature-advection, and latent heat release terms.

\begin{tabular}{lccc}
\hline \hline \multirow{2}{*}{ Time } & \multicolumn{3}{c}{ Adiabatic cooling versus } \\
\cline { 2 - 4 } & $\begin{array}{c}\text { Vorticity } \\
\text { advection }\end{array}$ & $\begin{array}{c}\text { Temperature } \\
\text { advection }\end{array}$ & $\begin{array}{c}\text { Latent heat } \\
\text { release }\end{array}$ \\
\hline & \multicolumn{3}{c}{ Marine cyclone } \\
1200 UTC 18 January & -.673 & -.885 & -.373 \\
0000 UTC 19 January & -.777 & -.916 & -.491 \\
1200 UTC 19 January & -.657 & -.909 & -.620 \\
24-h averages & -.702 & -.903 & -.495 \\
& & & \\
& & Land cyclone & \\
1200 UTC 20 January & -.544 & -.833 & -.531 \\
0000 UTC 21 January & -.489 & -.897 & -.512 \\
1200 UTC 21 January & -.562 & -.779 & -.468 \\
24-h averages & -.548 & -.836 & -.504 \\
\hline
\end{tabular}



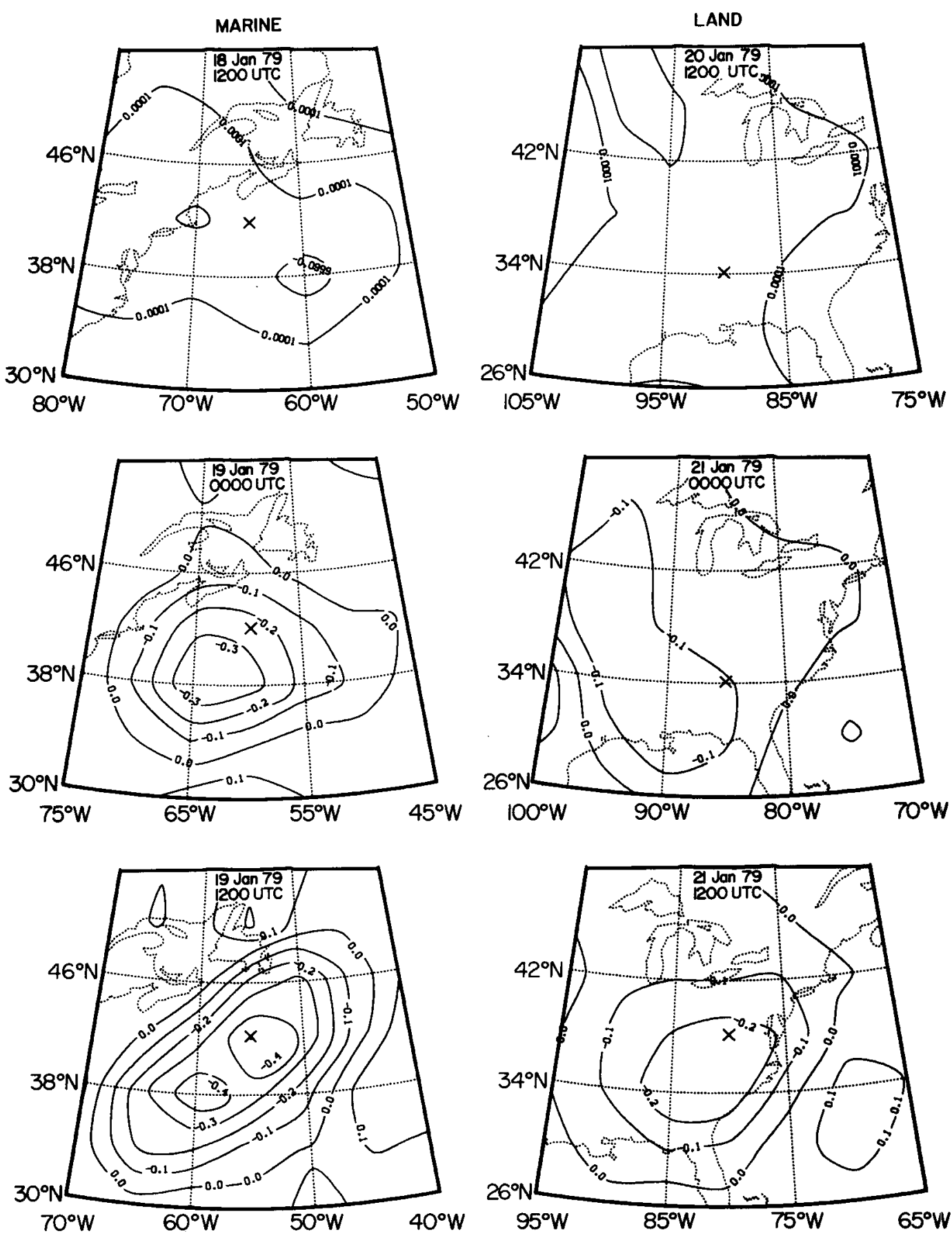

FIG. 19. As in Fig. 15, for the contribution due to friction.

a result similar to that noted by Manobianco (1989b), Fantini (1990), and Kuo et al. (1991). However, south and west of the marine cyclone there was a large positive contribution to the vorticity change. This reflects the large temperature difference between the cold air streaming southeastward off the continent and the warm sea surface temperatures of the Gulf Stream in the western Atlantic off the east coast of the United States. In satellite photos of the marine cyclone (not shown), open cellular convection and cloud streets were observed, again agreeing with the observations of Gyakum (1983a). An expected by-product of this sensible heating would be a lowering of the static stability in the boundary layer (Nuss and Anthes 1987; Sanders 1986; Manobianco 1989b). Thus, while the primary cyclone has already passed, this diminished static stability would establish a more favorable environment for the development of any subsequent cyclone that 

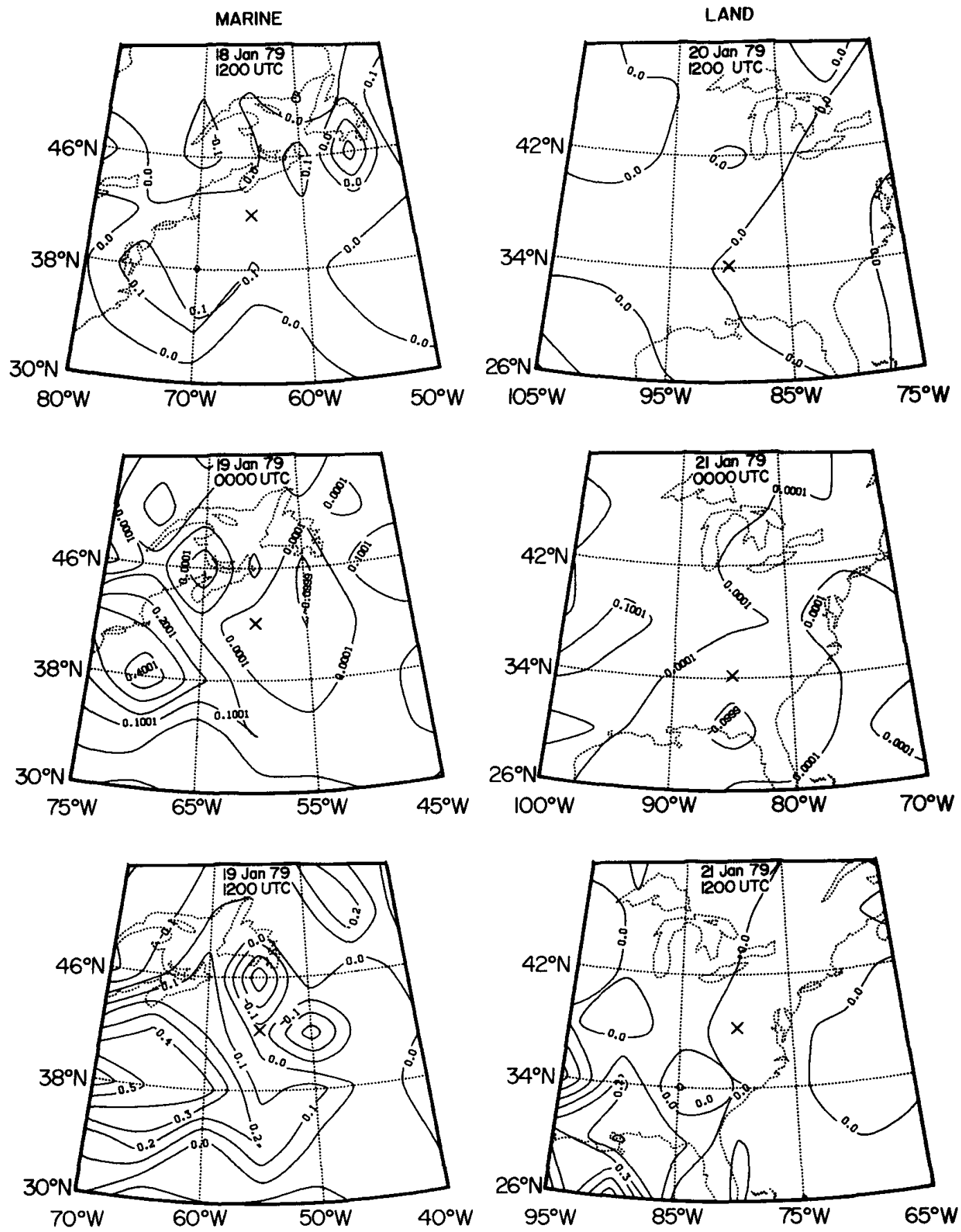

FIG. 20. As in Fig. 15, for the contribution due to sensible heating.

might pass over the area. A similar philosophy has been expressed by Kuo et al. (1991) in the more general context of both sensible heat and moisture fluxes from the lower boundary. Clearly, although viewing the role of boundary fluxes at the time of explosive cyclogenesis is of interest, instantaneous diagnoses alone are not adequate to completely establish the importance of such fluxes in these developments.

\section{b. Cyclone area averages}

Recall that nine-point area averages were calculated to represent the geostrophic vorticity tendencies near the cyclone center, thus isolating the development component of the vorticity tendency. In the marine case (Fig. 21), explosive development was initiated primarily by cyclonic-vorticity advection. Then both 
MARINE

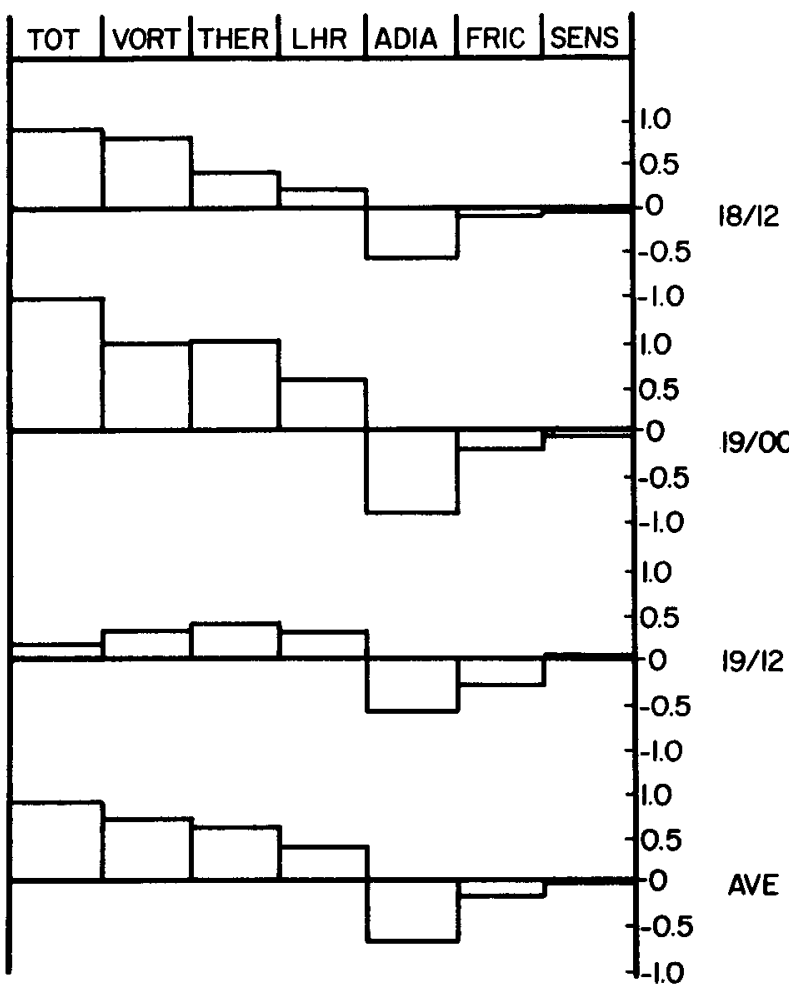

FIG. 21. Nine-point-averaged contributions to the total geostrophic vorticity tendency $\left(10^{-9} \mathrm{~s}^{-2}\right)$ for all terms in the extended ZwackOkossi equation with smoothed thermodynamic terms for the marine cyclone.

temperature advection and latent heat release increased to become comparable to vorticity advection. In contrast, adiabatic cooling in the ascending air and friction damped the three primary development terms, while sensible heating exerted a consistently small influence in the cyclone domain.

In the weaker land case (Fig. 22), the initial stage of explosive development was dominated by an already well-developed latent heat release field primarily resulting from convection that developed along the Gulf coast just south of the cyclone center (see Fosdick and Smith 1991, Fig. 4). However, as explosive development progressed, latent heat release was joined by cyclonic vorticity and warm-air advection. Again, adiabatic cooling and friction acted to inhibit development, while sensible heating was small.

In both cases, explosive development occurred as cyclonic-vorticity advection, warm-air advection, and latent heat release combined to force significant geostrophic vorticity increases (see first two map times in Figs. 21 and 22). However, the relative contribution of these mechanisms differed for the two cases. In the marine cyclone, the influences of vorticity and temperature advection dominated, while in the land cyclone, latent heat release played a stronger role. By the final map time, all three terms in the marine case and the latter two in the land case had decreased substantially in the cyclone domain, which when combined with the diabatic and frictional influences resulted in much slower development or decay of both cyclones.

\section{c. Vertical profiles and cross sections}

While the contributions to the total vorticity tendencies made by each integrated forcing process to surface development at $950 \mathrm{mb}$ has been demonstrated in the preceding sections, no details about the vertical structure and distribution of each forcing process have been provided. To accomplish this, vertical profiles of forcing terms and quantities contributing to those terms are discussed. The vertical profiles are nine-point averaged over the same domain used in the previous section. In addition, cross sections are examined. These cross sections were constructed along the latitude line that passes through the cyclone center within the domain specified in Table 1 and were made for the vorticity and temperature advection.

The vertical profiles of relative vorticity and absolutevorticity advection are shown in Fig. 23. The relative vorticity profile for the marine case started the period with a maximum near $250 \mathrm{mb}$ and smaller values close to the surface. For the land case, the relative vorticity profile started the explosive development period with

\section{LAND}

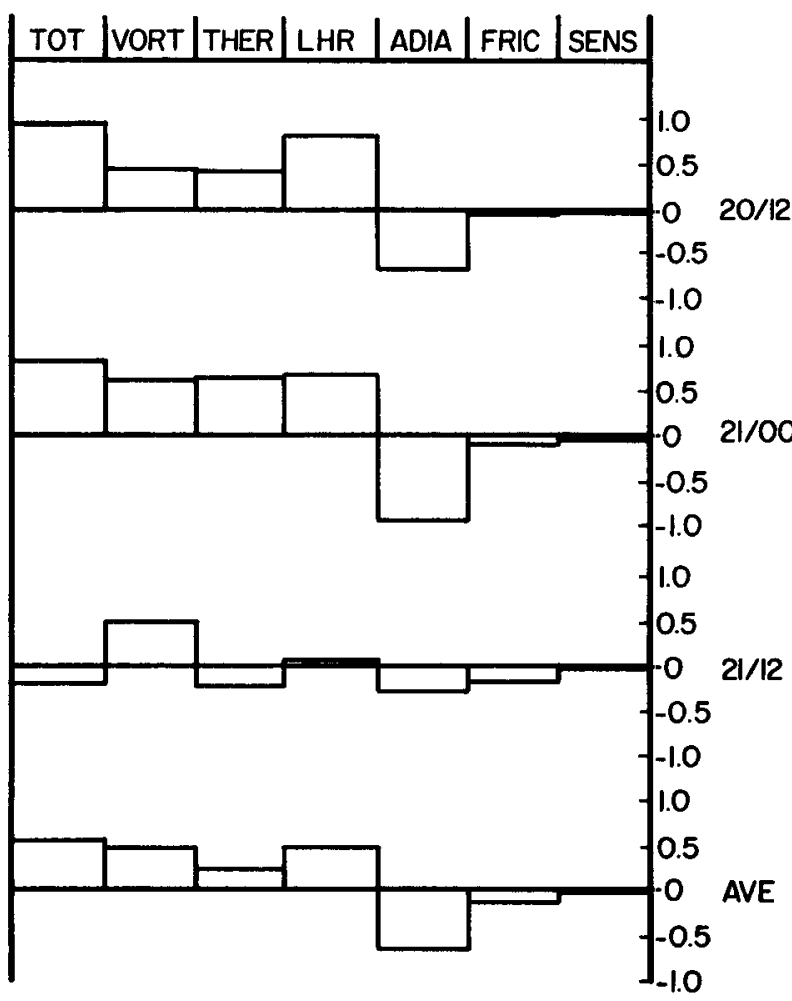

FIG. 22. As in Fig. 21 for the land cyclone. 
a maximum at $850 \mathrm{mb}$ and near-zero vorticities in the upper troposphere in a fashion similar to the composite profiles of MacDonald and Reiter (1988). Differences in the upper portion of the profiles for the two cases can be explained by recalling the position of the two cyclones relative to their respective jet streams (see Figs.
2-7). While the marine cyclone was located on the cyclonic side at all three map times, the land cyclone was located on the anticyclonic side until the final map time.

The vertical profiles of vorticity advection at all map times showed maximum cyclonic-vorticity advection
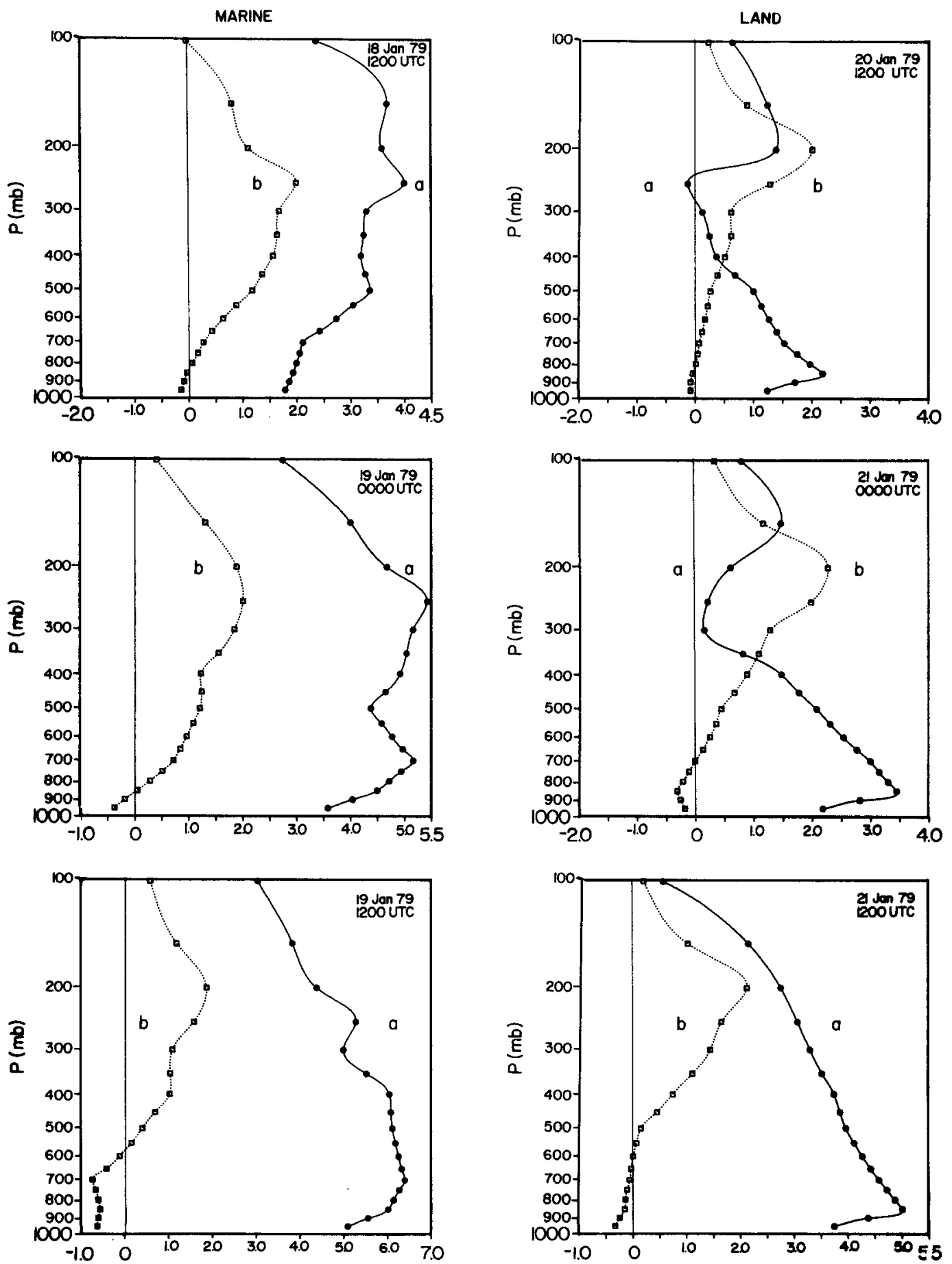

FIG. 23. Vertical profiles of (a) relative vorticity $\left(10^{-5} \mathrm{~s}^{-1}\right)$. (b) horizontal vorticity advection $\left(10^{-9} \mathrm{~s}^{-2}\right)$ for the marine cyclone (left) and land cyclone (right). 
(CVA) in the upper troposphere at the level of maximum winds, again similar to the results of MacDonald and Reiter (1988), and negative vorticity advection near the surface. In both cases, the upper-tropospheric maximum was largest at the middle map time. In the lower troposphere the vorticity advection, which was initially close to zero, became increasingly anticyclonic through a deeper layer. This explains why the ninepoint-averaged vorticity advection (Figs. 21 and 22) was largest at the middle map time. These results are consistent with a tilted baroclinic wave. As the wave develops, the upper-air trough and the area of maximum CVA in the upper troposphere overtakes the surface cyclone. This is seen in the vertical cross sections for this term (Fig. 24). Throughout the development period, the area of maximum CVA moved from a position upstream to a position downstream from the surface cyclone, while anticyclonic-vorticity advection prevailed at lower levels through a progressively deeper layer.

The vertical profiles of temperature advection and the Laplacian of temperature advection are shown in Fig. 25. Similar to the vorticity advection, the temperature-advection profiles also show the forcing due to warm-air advection to be strongest near $250 \mathrm{mb}$ and at the middle map times. This maximum occurred as a result of a warm pool found at high levels in the upper-air trough region, upstream from the surface cy-
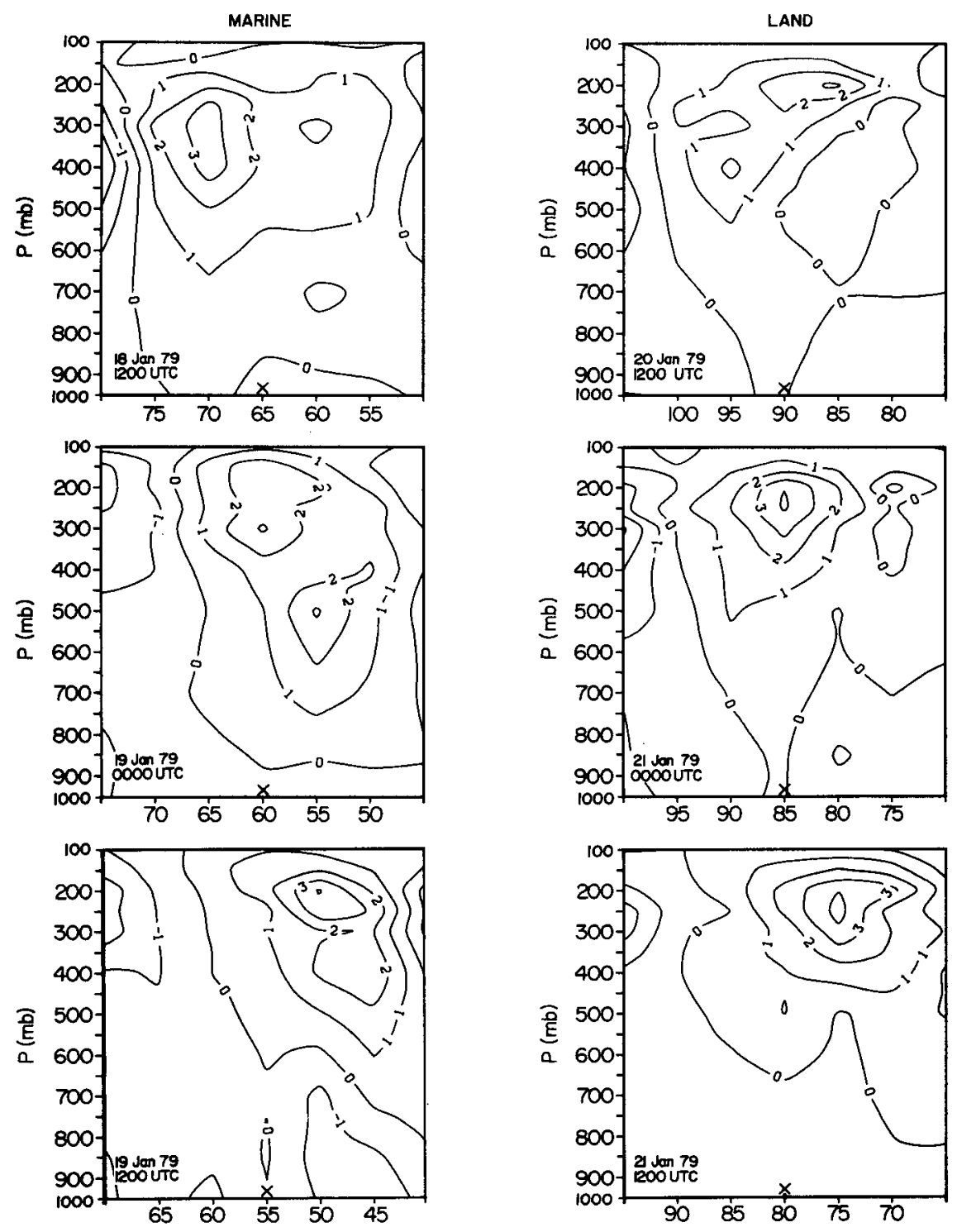

FIG. 24. Vertical cross sections of horizontal vorticity advection $\left(10^{-9} \mathrm{~s}^{-2}\right)$ taken across the center latitude of the marine cyclone (left) and land cyclone (right). The " $X$ " denotes the grid point with minimum sea level pressure. 

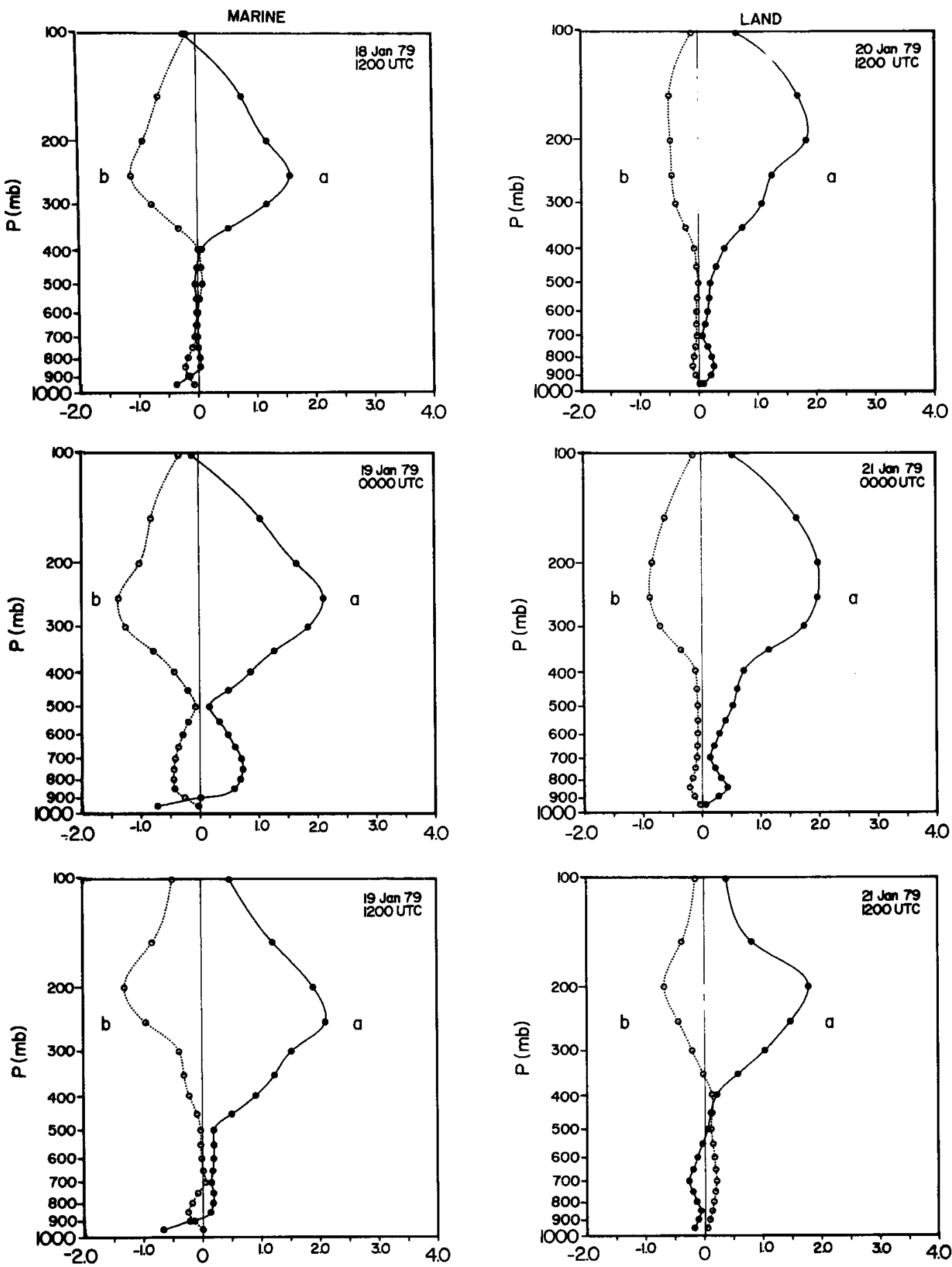

FIG. 25. Vertical profiles of (a) horizontal temperature advection $\left(10^{-4} \mathrm{~K} \mathrm{~s}^{-1}\right)$. (b) Laplacian of horizontal temperature advection $\left(10^{-15} \mathrm{~K} \mathrm{~s}^{-1} \mathrm{~m}^{-2}\right.$ ) for the marine cyclone (left) and land cyclone (right).

clone for both cases. This warm-air pool corresponds to undulations in the tropopause in which warmer stratospheric air is found above the upper-air trough in a midlatitude wave, as demonstrated by Hirschberg and Fritsch (1991a,b). Hirschberg and Fritsch also show that temperature advections at this level are as common as temperature advections in the lower troposphere and, when superimposed up lower-level baroclinic zones or in combination with other forcing mechanisms, can enhance surface development.

These profiles also show a secondary maximum of warm-air advection in the lower troposphere near 850 
$\mathrm{mb}$ in both cases. The secondary maximum near 850 $\mathrm{mb}$ is due to low-level baroclinicity typically associated with surface cyclones. These profiles show warm-air advection virtually through the entire depth of the column for both cases with the exception of the final map time of the land case, which shows lower-tropospheric cold-air advection. This cold advection completely neutralized the higher-level warm advection. The cross sections of temperature advection (Fig. 26) confirm these results, showing the upper-tropospheric maxima over the surface cyclone for the first two map times in both cases. For the final map time, the temperatureadvection maxima were larger but were downstream from the surface cyclone. Thus, the advections were smaller in the immediate cyclone domain. These results explain why the nine-point-averaged cyclone domain forcing due to temperature advection was also strongest at the middle map times.

The vertical profiles of the static stability parameter $S$ and vertical motion are shown in Fig. 27. At all map times for both cases, the static stability parameter was relatively small near the surface (average for all map times is $4.40 \times 10^{-2} \mathrm{~K} \mathrm{mb}^{-1}$ ) and increased with height to a value close to $1 \mathrm{~K} \mathrm{mb}^{-1}$ in the upper troposphere. The profiles indicate a more rapid rise of $S$ in the upper troposphere, starting at $300 \mathrm{mb}$, reflecting a rapid increase in the vertical gradient of potential temperature. The magnitude of vertical motion for the marine and land cases maximize around 600 and $300 \mathrm{mb}$, respectively. The vertical motions were larger for the land case, and in both cases were largest at the middle map time.
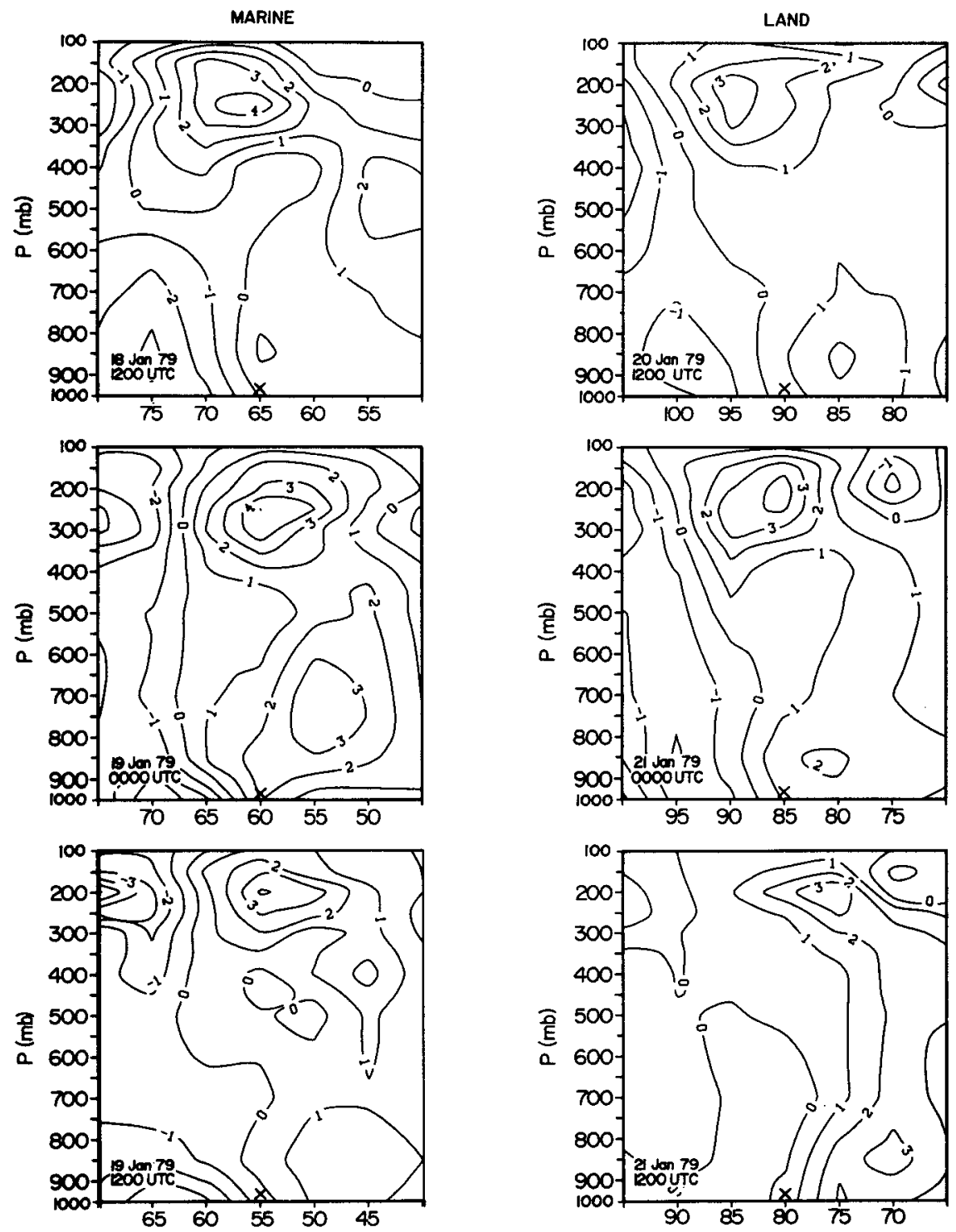

FIG. 26. As in Fig. 24, for horizontal temperature advection $\left(10^{-4} \mathrm{~K} \mathrm{~s}^{-1}\right)$. 

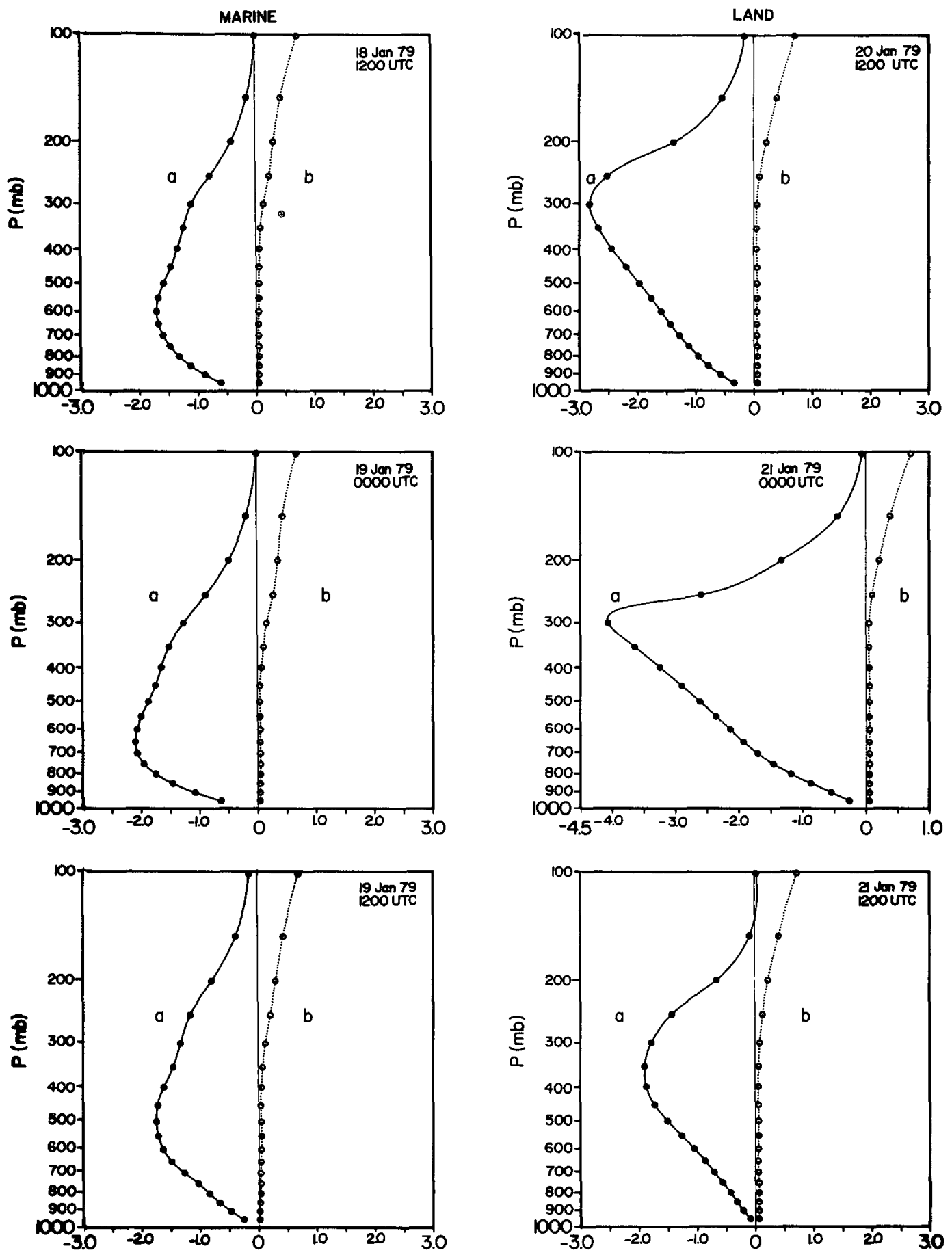

FIG. 27. Vertical profiles of (a) vertical motion $\omega\left(\mu \mathrm{b} \mathrm{s}^{-1}\right)$ and (b) static stability parameter $S\left(\mathrm{~K} \mathrm{mb}^{-1}\right)$ for the marine cyclone (left) and land cyclone (right).

The vertical profiles of the product of static stability and vertical motion $(S \omega)$ and the Laplacian of $S \omega$ are shown in Fig. 28. These profiles are opposite in sign to the other thermodynamic profiles and more complex. The product of $S \omega$ exhibits a primary maximum in the upper troposphere in both cases, with a secondary maximum appearing in the lower troposphere for the marine case. In the marine case, the primary $S \omega$ maximum can be explained by the larger values of $S$, while the secondary maximum is the result of the verticalmotion maximum. For the land case, the $S \omega$ maximum in the upper troposphere is the result of both the large $S$ values and maximum vertical velocity.

The vertical profiles of latent heating rate and the 

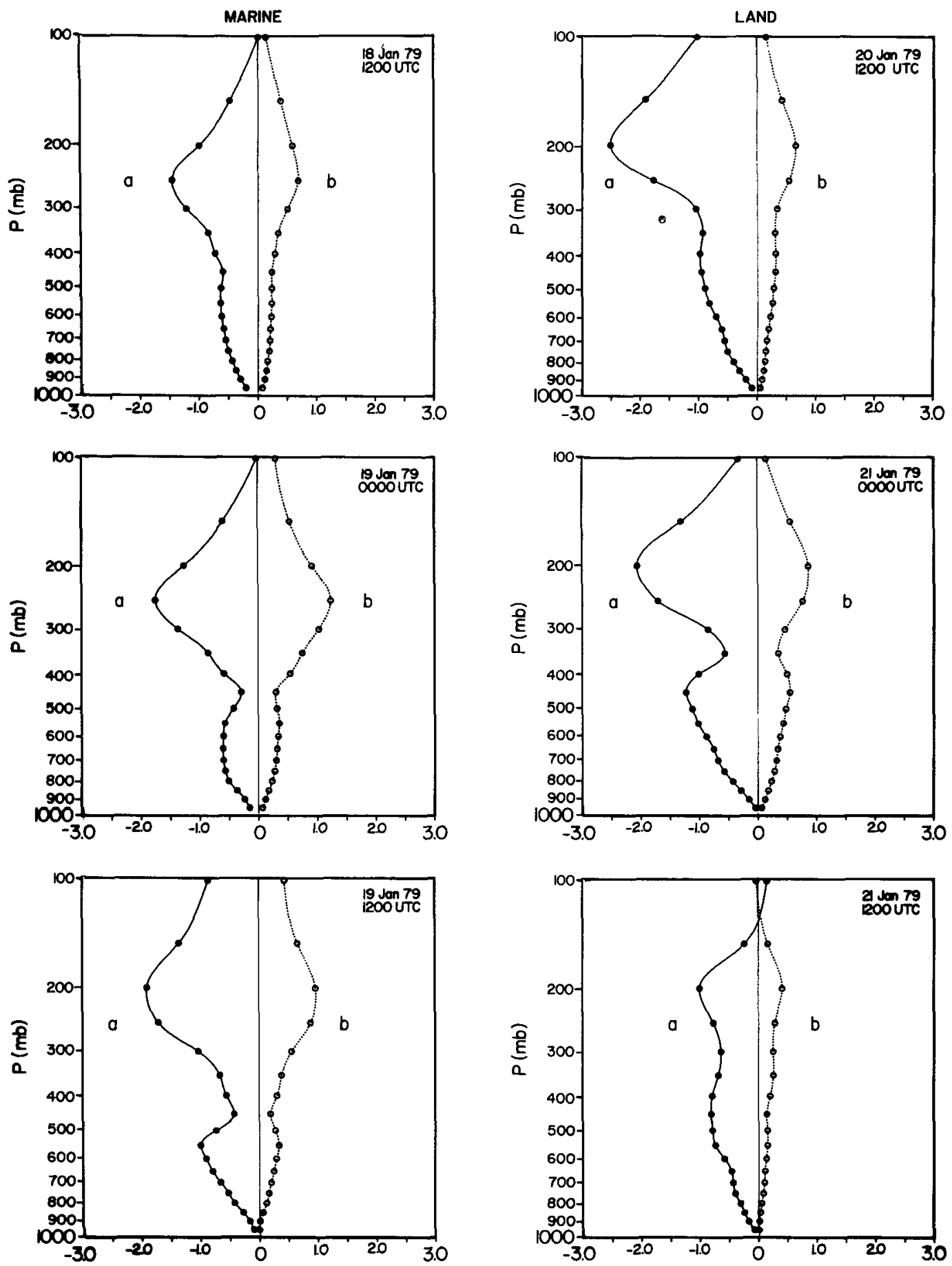

FIG. 28. Vertical profiles of (a) adiabatic cooling $\left(10^{-4} \mathrm{~K} \mathrm{~s}^{-1}\right)$ and (b) Laplacian of adiabatic cooling $\left(10^{-15} \mathrm{~K} \mathrm{~s}^{-1} \mathrm{~m}^{-2}\right)$ for the marine cyclone (left) and land cyclone (right).

Laplacian of the latent heating rate are shown in Fig. 29 . In the marine case, the latent heat release maximizes between 850 and $600 \mathrm{mb}$. The layer of maximum latent heat release was deepest at the middle map time, and the maximum was lowest at the final map time. In the land case, the initial latent heating rate maxi- mum was at $450 \mathrm{mb}$ and was large through a deep layer of the troposphere. For the following two map times, the latent heat release maximum lowered to 650 $\mathrm{mb}$, but was still at a higher level than for the marine case maxima. The shallower layer of LHR by the final map time for both cases suggests that the deeper, thicker 

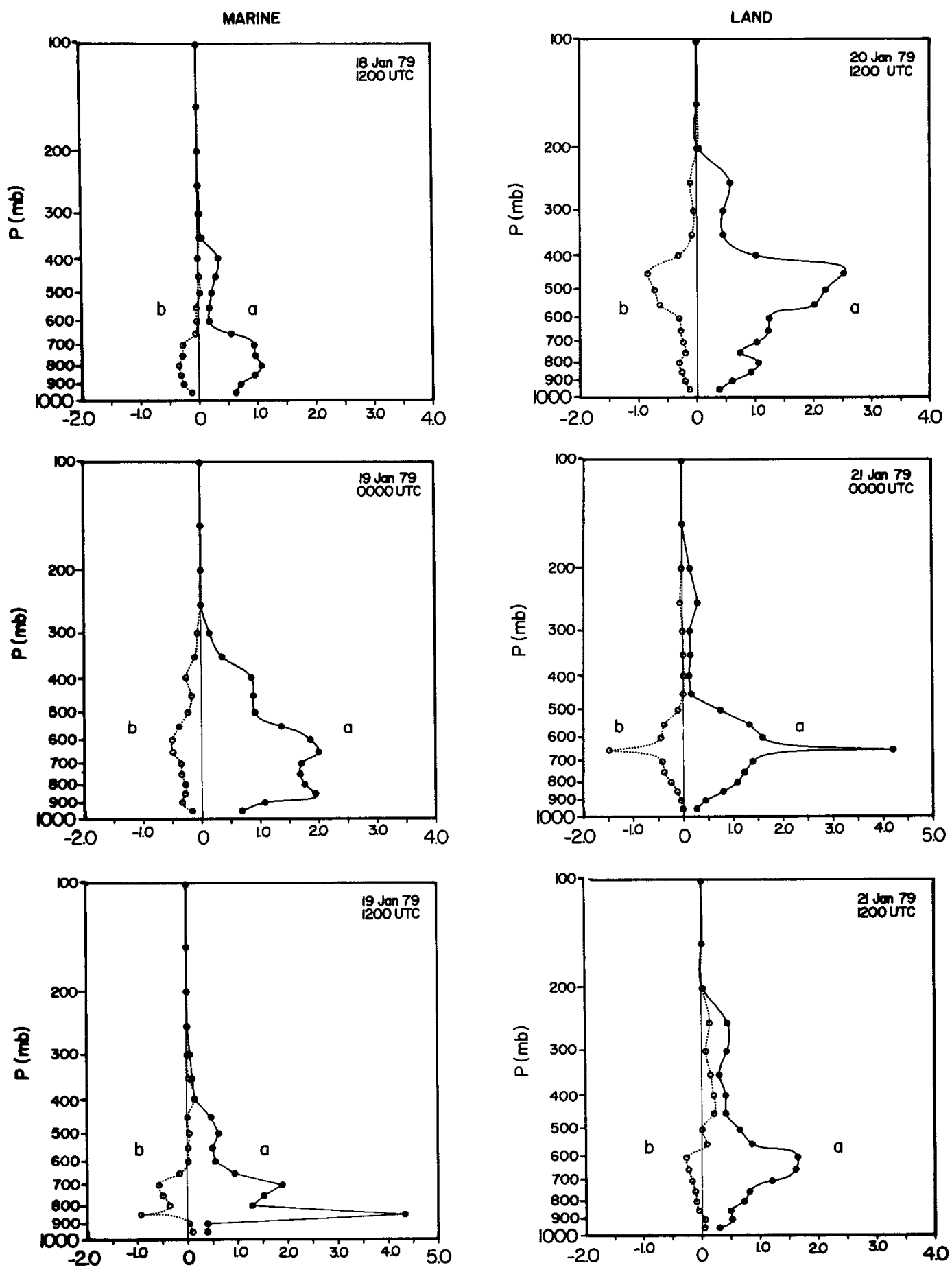

FiG. 29. Vertical profiles of (a) latent heat release $\left(10^{-4} \mathrm{~K} \mathrm{~s}^{-1}\right)$ and (b) Laplacian of latent heat release $\left(10^{-15} \mathrm{~K} \mathrm{~s}^{-1} \mathrm{~m}^{-2}\right)$ for the marine cyclone (left) and land cyclone (right).

convective clouds had moved farther away from the center and that the center of the low was dominated by more stratiform clouds. The higher (lower) LHR maxima coincide with higher (lower) vertical-motion maxima for the land (marine) case, suggesting, as noted by Gyakum (1983a), that the distribution of diabatic heating is influenced by the vertical-motion profile. Furthermore, it is apparent that the larger latent heating influence for the land cyclone compared with the marine cyclone for the first map time (see Figs. 21 and 22) occurred as a result of greater latent heat release throughout most of the column in the land cyclone 
and not as a result of a lower-level heating maximum, as suggested by Anthes and Keyser (1979) and Gyakum (1983b).

\section{Summary}

A diagnosis of two explosively developing cyclones that occurred within a 4-day period was performed using 950-mb geostrophic vorticity tendencies derived from the Zwack-Okossi development equation. The first cyclone developed explosively over the Atlantic Ocean off the coast of New England, while the second developed over the southeastern United States. Tendencies derived from three forms of the Z-O equation were compared with 12-h finite-difference observed vorticity changes. The resulting tendencies were overestimated by all three forms of the $\mathrm{Z}-\mathrm{O}$ equation. These overestimates were traced to errors in ageostrophic vorticity tendency estimates and $2 \Delta x$ noise in the thermodynamic terms calculations. A five-point smoothing technique was employed to remove the noise, resulting in significant improvement in the $\mathrm{Z}-\mathrm{O}$ equation calculations and establishing the extended form of the equation as computationally superior at the time and space scales represented by the GLA analysis fields.

The results demonstrate that cyclonic-vorticity advection, dominated by upper-tropospheric advections, was the most consistent contributor to the $950-\mathrm{mb}$ geostrophic vorticity increases found within and downstream from the cyclone centers. However, warmair advection and latent heat release also contributed in varying degrees to the vorticity increases. For the more-rapidly deepening marine cyclone, the influences of vorticity and temperature advection dominated the cyclone development, while latent heat release played a significant but smaller role. For the land cyclone, vorticity increases forced by latent heat release were larger than either vorticity or temperature advection. The positive temperature-advection contributions were dominated by warm-air advections in the upper troposphere, while latent heat release dominated in the lower-to-middle troposphere for both cyclones. The adiabatic-cooling term contributed negatively to the development of the cyclones and was of the same order as the individual positively contributing processes. The boundary-layer processes also contributed negatively to the development of the cyclone in general, but were at least one order of magnitude smaller than the other terms.

In conclusion, it has been demonstrated that the $\mathrm{Z}-$ $O$ equation is an effective tool for diagnosing synopticscale cyclone development. Especially useful is the ability of the Z-O equation to explicitly account for the contribution of all layers of the atmosphere to surface development, thus confirming the importance of upper-air support during surface cyclogenesis. Results indicate that the upper-air support is particularly strong for the cases examined here in the upper troposphere and lower stratosphere, where both cyclonic-vorticity and warm-air advections maximize. Finally, it is seen that explosive development is, as suggested by Uccellini et al. (1987), a result of the complementary forcing by both dynamic and thermodynamic processes. When one or more of the development mechanisms becomes sufficiently weak, the sum of these mechanisms will be unable to overcome the inhibiting influence of adiabatic cooling, and development will cease.

Acknowledgments. The authors are grateful to Doug Miller and Melinda Hunter for figure drafting and to the referees for their very helpful suggestions. This research was sponsored by the National Aeronautics and Space Administration under Grant NAG8-764.

\section{REFERENCES}

Anthes, R. A., and D. Keyser, 1979: Test of fine-mesh model over Europe and the United States. Mon. Wea. Rev., 107, 963-984.

Baker, W. E., 1983: Objective analysis and assimilation of observational data from FGGE. Mon. Wea. Rev., 111, 328-342.

Cressman, G., 1959: An operational objective analysis system. Mon. Wea. Rev., 87, 367-374.

Davis, C. A., and K. A. Emanuel, 1988: Observational evidence for the influence of surface heat fluxes on rapid maritime cyclogenesis. Mon. Wea. Rev., 116, 2649-2659.

Edmon, H. J., and D. G. Vincent, 1976: An application of two tropical parameterization schemes of convective latent heat release in middle latitudes. Mon. Wea. Rev., 104, 1141-1153.

Elsberry, R. L., and P. J. Kirchoffer, 1988: Upper-level forcing of explosive cyclogenesis over the ocean based on operationally analyzed fields. Wea. Forecasting, 3, 205-216.

Fantini, M., 1990: The influence of heat and moisture fluxes from the ocean on the development of baroclinic waves. J. Atmos. Sci., 47, 840-855.

Fosdick, E. K., and P. J. Smith, 1991: Latent heat release in an extratropical cyclone that developed explosively over the southeastern United States. Mon. Wea. Rev., 119, 193-207.

Gyakum, J. R., 1983a: On the evolution of the $Q E I I$ storm. Part I: Synoptic aspects. Mon. Wea. Rev., 111, 1137-1155.

, 1983b: On the evolution of the QE II storm. Part II: Dynamic and thermodynamic structure. Mon. Wea. Rev., 111, 1156-1173.

Haltiner, G. J., and F. L. Martin, 1957: Dynamical and Physical Meteorology. McGraw-Hill, 470 pp.

Hirschberg, P. A., and J. M. Fritsch 1991a: Tropopause undulations and the development of extratropical cyclones. Part I: Overview and observations from a cyclone event. Mon. Wea. Rev., 119, 496-517.

- and - 1991b: Tropopause undulations and the development of extratropical cyclones. Part II: Diagnostic analysis and conceptual model. Mon. Wea. Rev., 119, 518-550.

Kalnay, E., R. Balgovind, W. Chao, D. Edelmann, J. Pfaendter, L. Takacs, and K. Takano, 1983: Documentation of the GLAS fourth-order general circulation model. Vol. I. NASA Tech. Memo 86064, Goddard Space Flight Center.

Kalnay-Rivas, E., A. Bayliss, and J. Storch, 1977: The 4th order GISS model of the global atmosphere. Beitr. Phys. Atmos., 50, 299-311.

Krishnamurti, T. N., 1968: A diagnostic balance model for studies of weather systems of low and high latitudes, Rossby number less than 1. Mon. Wea. Rev., 96, 197-207.

- and W. J. Moxim, 1971: On parameterization of convective and nonconvective latent heat release. J. Appl. Meteor, 10, 313.

Kuo, H. L., 1965: On formation and intensification of tropical cyclones through latent heat release by cumulus convection. $J$. Atmos. Sci., 22, 40-63.

, 1974: Further studies of the parameterization of the influence 
of cumulus convection on a large-scale flow. J. Atmos. Sci., 31, 1232-1240.

Kuo, Y. H., and R. J. Reed, 1988: Numerical simulation of an explosively deepening cyclone in the eastern Pacific. Mon. Wea. Rev., 116, 2081-2105.

$\longrightarrow,-$, and S. Low-Nam, 1991: Effects of surface energy fluxes during the early development and rapid intensification stages of seven explosive cyclones in the western Atlantic. Mon. Wea. Rev., 119, 457-476.

Lin, S. C., and P. J. Smith, 1979: Diabatic heating and generation of available potential energy in a tornado-producing extratropical cyclone. Mon. Wea. Rev., 107, 1169-1183.

MacDonald, B. C., and E. R. Reiter, 1988: Explosive cyclogenesis over the eastern United States. Mon. Wea. Rev., 116, 15681586.

Manobianco, J., 1989a: Explosive east coast cyclogenesis over the west-central Atlantic Ocean: A composite study derived from ECMWF operational analyses. Mon. Wea. Rev., 117, 2365-2383.

_ 1989 b: Explosive east coast cyclogenesis: Numerical experimentation and model-based diagnostics. Mon. Wea. Rev., 117, 2384-2405.

Miller, B. L., and D. G. Vincent, 1987: Convective heating and precipitation estimates for the tropical South Pacific during FGGE, 10-18 January 1979. Quart. J. Roy. Meteor. Soc., 113, 189212.

Nuss, W. A., and R. A. Anthes, 1987: A numerical investigation of low-level processes in rapid cyclogenesis. Mon. Wea. Rev., 115 , 2728-2743.

Petterssen, S., 1956: Weather Analysis and Forecasting. Vol. I. 2d ed. McGraw-Hill, 428 pp.

Reed, R. J., and M. D. Albright, 1986: A case study of explosive cyclogenesis in the eastern Pacific. Mon. Wea. Rev., 114, 2297 2319.

- A. J. Simmons, M. D. Albright, and P. Unden, 1988: The role of latent heat release in explosive cyclogenesis: Three examples based on ECMWF operational forecasts. Wea. Forecasting, 3, 217-229.

Robertson, F. R., 1985: IR precipitation estimates in the South Pacific during FGGE SOP-I. Preprints, 16th Conf. on Hurricanes and Tropical Meteorology, Houston, TX, Amer. Meteor. Soc., 4849.
Roebber, P. J., 1984: Statistical analysis and updated climatology of explosive cyclones. Mon. Wea. Rev., 112, 1577-1589.

Rogers, E., and L. F. Bosart, 1986: An investigation of explosively deepening oceanic cyclones. Mon. Wea. Rev., 114, 702-718.

Sanders, F., 1986: Explosive cyclogenesis over the west central North Atlantic Ocean 1981-1984. Part II: Composite structure and mean behavior. Mon. Wea. Rev., 114, 1781-1794.

- - and J. R. Gyakum, 1980: Synoptic-dynamic climatology of the "bomb." Mon. Wea. Rev., 108, 1589-1606.

Smith, P. J., P. M. Dare, and S.-J. Lin, 1984: The impact of latent heat release on synoptic scale vertical motions and the development of an extratropical cyclone system. Mon. Wea. Rev., 112, 2421-2430.

Tsou, C.-H., and P. J. Smith, 1990: The role of synoptic/planetaryscale interactions during the development of a blocking anticyclone. Tellus, 42A, 174-193.

- - - - and P. M. Pauley, 1987: A comparison of adiabatic and diabatic forcing in an intense extratropical cyclone system. Mon. Wea. Rev., 115, 763-786.

Uccellini, L. W., and P. J. Kocin, 1987: The interaction of jet streak circulations during heavy snow events along the East Coast of the United States. Wea. Forecasting, 1, 289-308.

,,-- R. A. Petersen, C. H. Wash, and K. F. Brill, 1984: The Presidents' Day cyclone of 18-19 February 1979: Synoptic overview and analysis of the subtropical jet streak influencing the pre-cyclogenetic period. Mon. Wea. Rev., 112, 31-55.

- D. Keyser, K. F. Brill, and C. H. Wash, 1985: Presidents' Day cyclone of 18-19 February 1979: Influence of upstream trough amplification and associated tropopause folding on rapid cyclogenesis. Mon. Wea. Rev., 113, 962-988.

-, R. A. Petersen, K. F. Brill, P. J. Kocin, and J. J. Tuccillo, 1987: Synergistic interactions between an upper-level jet streak and diabatic processes that influence the development of a lowlevel jet and a secondary coastal cyclone. Mon. Wea. Rev., 115, 2227-2261.

Vincent, D. G., G. B. Pant, and H. J. Edmon, 1977: Generation of available potential energy of an extratropical cyclone system. Mon. Wea. Rev., 105, 1252-1265.

Zwack, P., and B. Okossi, 1986: A new method for solving the quasigeostrophic omega equation by incorporating surface pressure tendency data. Mon. Wea. Rev., 114, 655-666. 